\title{
EFFECTS OF ELECTROMAGNETIC TREATMENT ON GROWTH AND PHOTOSYNTHESIS OF THREE COMMON FRESHWATER PHYTOPLANKTON SPECIES
}

\author{
by \\ Jennifer Bello Levieva \\ Honours Bachelor of Science \\ University of Toronto, Toronto, Ontario \\ 2017
}

A Professional Project Paper presented to Ryerson University

in partial fulfillment of the requirement for the degree of

Master of Applied Science

in the Program of

Environmental Applied Science and Management

Toronto, Ontario, Canada, 2020

(C) Jennifer Bello Levieva 2020 


\section{AUTHOR'S DECLARATION}

I hereby declare that I am the sole author of this project paper. This is a true copy of the project paper including any required final revisions, as accepted by my examiners.

I authorize Ryerson University to lend this project paper to other institutions or individuals for the purpose of scholarly research I further authorize Ryerson University to reproduce this project paper by photocopying or by other means, in total or in part, at the request of other institutions or individuals for the purpose of scholarly research.

I understand that my project paper may be made electronically available to the public. 
Effects of Electromagnetic Treatment on Growth and Photosynthesis of Three Common Freshwater Phytoplankton Species

Master of Applied Science, 2020

Jennifer Bello Levieva

Environmental Applied Science and Management

Ryerson University

\begin{abstract}
A study was done using three common freshwater phytoplankton species of Chlorella vulgaris, Microcystis aeruginosa, and Cyclotella pseudostelligera, where the effects of two low power electromagnetic fields (EMF) on phytoplankton growth and photosynthesis were assessed. Growth was quantified by direct cell count and photosynthetic rates were measured as oxygen production with an oxygen probe. Results showed that maximum densities of C. vulgaris and $M$. aeruginosa were increased by application of an EMF, as was the growth rate of $M$. aeruginosa, and there were also differences in respiration rates. C. pseudostelligera, in contrast, had lower growth rates and maximum cell densities when exposed to EMF. These results may be attributed to differences in cell structures, particularly differences in the composition of cell membranes, and charge environments. Future studies should focus on mixed cultures as well as examining how specific cellular responses such as nutrient uptake may differ in response to EMF.
\end{abstract}




\section{ACKNOWLEDGEMENTS}

First and foremost, I would like to extend my deepest gratitude to my supervisors to Dr. Andrew Laursen and Dr. Vadim Bostan, who have provided me with constant support and guidance over the past few years. Thank you for always encouraging me throughout my research endeavors and keeping me in high spirits even when things got difficult, as it really helped me get to this point in my graduate career. I will always look back on graduate school and remember the drive and perseverance I was able to obtain from being able to work with such amazing mentors. Thank you.

I would also like to thank the friends I have made at EnSciMan, as you were all such amazing support through all of the good and tough times. I wouldn't have made it this far

without all of your constant support, and I am more than happy to say that I have made lifelong friends during my time here. I would also like to thank the friends that I have had since before coming to EnSciMan, as you were always in my corner when I needed you most, as well as when short fun breaks were needed from writing and experiments.

Last but definitely not least, I would like to thank my family for their endless support throughout my graduate career. I would not have gotten this far without your constant encouragements, criticisms, help, and love when I needed it most. Thank you for everything, there are not enough words to describe how grateful I am for everything. 


\section{TABLE OF CONTENTS}

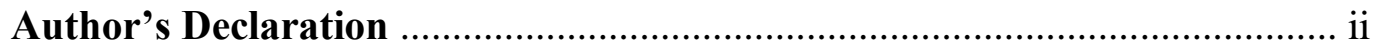

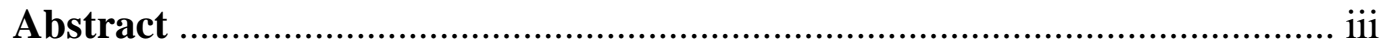

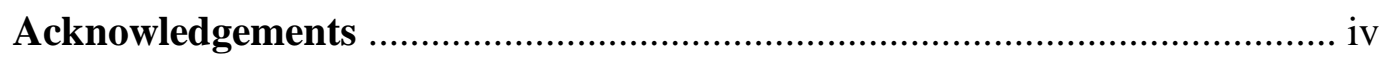

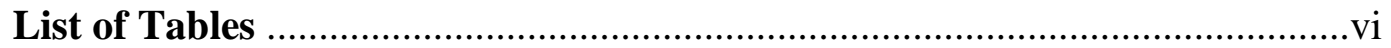

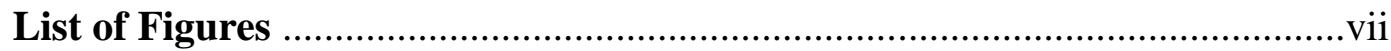

List of Abbreviations ..............................................................................ii

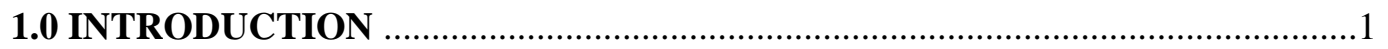

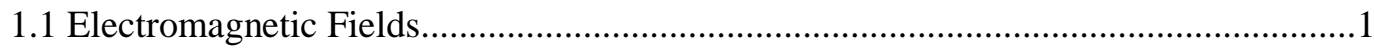

1.2 Effects of static electromagnetic fields on plant growth and photosynthesis...........2

1.3 Effects of oscillating electromagnetic fields on plant growth and photosynthesis.......6

1.4 Effects of oscillating electromagnetic fields on growth and photosynthesis or algae and

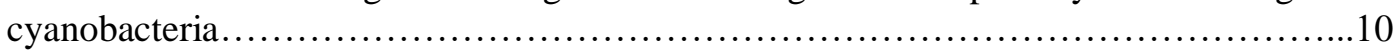

1.5 Rationale for Selection of Photosynthetic Organisms...............................12

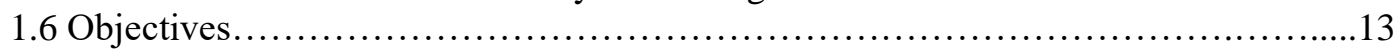

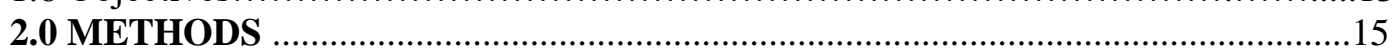

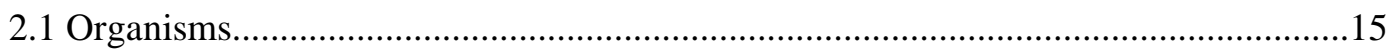

2.1.1 Selected Organisms and Rationale......................................................................15

2.1.2 Culturing Conditions for Organisms.................................................................15

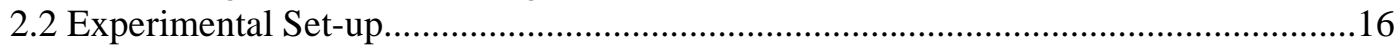

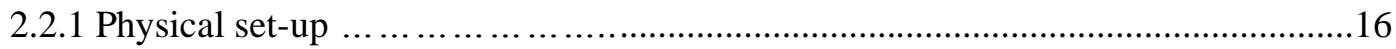

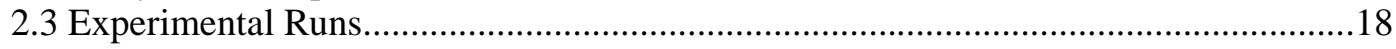

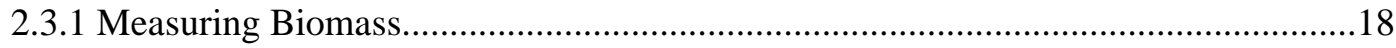

2.3.2 Measuring Photosynthetic and Respiration Rates....................................................19

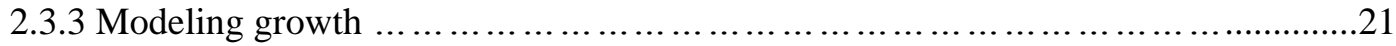

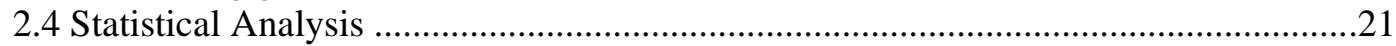

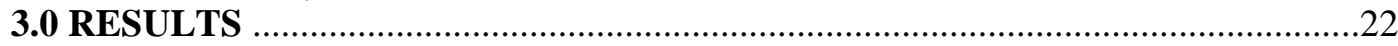

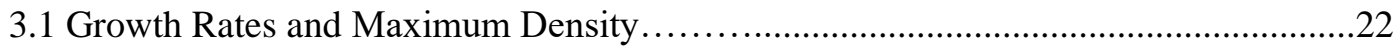

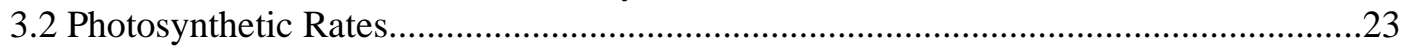

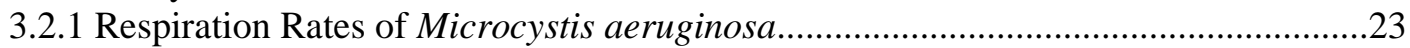

3.2.2 Respiration Rates of Cyclotella pseudostellgera ……………………………….......25

3.2.3 Respiration Rates of Chlorella vulgaris..................................................................26

3.3 Revisiting effects on Growth Rate, Maximum Cell Densities, and Photosynthesis of

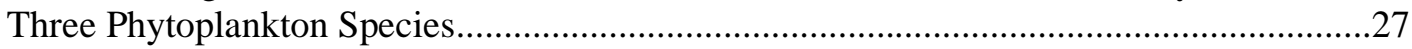

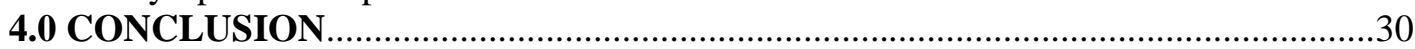

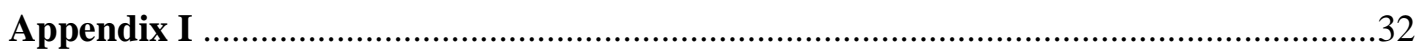

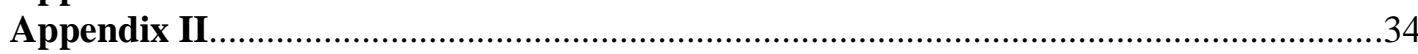

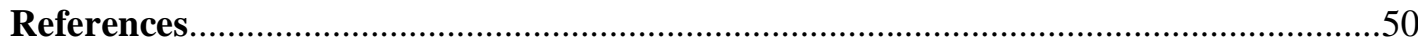




\section{LIST OF TABLES}

Table 3.1. Mean \pm standard error growth rates and carrying capacities across different electromagnetic

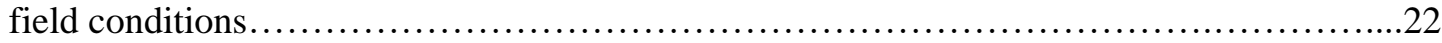




\section{LIST OF FIGURES}

Figure 2.1. Image of 3 out of the 9 total jars used as replicate experimental units

Figure 2.2. Chlorella vulgaris cells in the haemocytometer.............................................. 18

Figure 2.3. Experimental setup used for measuring respiration and photosynthetic rates of cell samples

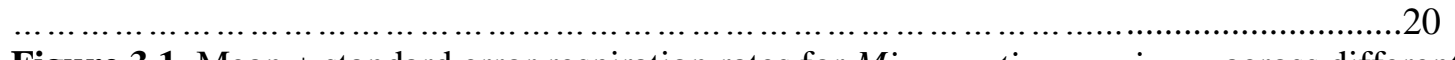

Figure 3.1. Mean \pm standard error respiration rates for Microcystis aeruginosa across different conditions. .24

Figure 3.2. Mean \pm standard error respiration rates for Cyclotella pseudostellgera across different conditions. .25

Figure 3.3. Mean \pm standard error respiration rates for Chlorella vulgaris across different conditions. 


\section{List of Abbreviations}

$\begin{array}{ll}\text { EMF } & \text { electromagnetic field } \\ \mathrm{mT} & \text { milli Tesla } \\ \mathrm{T} & \text { Tesla } \\ \mu \mathrm{T} & \text { micro Tesla } \\ \mathrm{nT} & \text { nano Tesla } \\ \mathrm{Hz} & \text { Hertz } \\ \mathrm{kHz} & \text { kilo Hertz } \\ \mu \mathrm{mol} & \text { micromole } \\ \mathrm{mmol} & \text { millimole } \\ \mathrm{OEMS} & \text { oscillating electromagnetic signal } \\ \text { C. vulgaris } & \text { Chlorella vulgaris } \\ \text { M. aeruginosa } & \quad \text { Microcystis aeruginosa } \\ \text { C. pseudostelligera Cyclotella pseudostelligera }\end{array}$




\section{Introduction}

\subsection{Electromagnetic Fields}

Electromagnetic fields (EMF) are a combination of electric and magnetic fields that can couple tightly together under certain conditions, such as in the event of a moving charge. On their own, electrical fields exist in a region of space if a charge experiences an electrical force, and magnetic fields exist when there are electrical charges in motion, such as a flow of an electrical current (IARC, 2002). It is also interesting to note that an oscillating magnetic field can generate an electric field perpendicular to the magnetic field and vice versa (IARC, 2002). Both forces are also characterized by magnitude, measured by a potential difference across a distance (IARC, 2002). This is typically expressed in units of Tesla (T), which convey the strength of the observed magnetic flux density (IARC, 2002), or in volts (V), which conveys the strength of the electrical force. Electromagnetic fields can also be classified based on the frequency with which they oscillate (i.e. frequency with which magnetic fields reverse), expressed in units of Hertz $(\mathrm{Hz})$, which measures the number of oscillations per second. For the purposes of this paper, electromagnetic fields are discussed as inclusive of electrical fields, magnetic fields, or both. This recognizes that a magnetic field can exist in the absence of an electrical field (e.g. a static magnetic field generated by permanent magnets spawns no orthogonal electrical field), just as an electrical field can exist in the absence of a magnetic field (e.g. a direct current will spawn no orthogonal magnetic field. As reviewed below, effects of electromagnetic fields on biological function have been demonstrated by treatment with electrical fields only, magnetic fields only, and both (i.e. where an oscillating current generates an orthogonal magnetic field). 


\subsection{Effects of static electromagnetic fields on plant growth and photosynthesis}

The geomagnetic field is a natural component of the Earth that has been produced at its fluid core for about 4 billion years. Over this time period, all living organisms have experienced its effects. Although they seem invisible, magnetic fields can affect biological activity, just as will other abiotic or biotic factors (Maffei, 2004). In particular, the sensitivity of plants to magnetic fields has been a topic of interest, as previous research has found that changes in magnetic fields have had positive effects on plant growth, development, evolution, and other specific life events that plants may encounter (Maffei, 2004). One of these specific life events includes the process of photosynthesis, which consists of plant cells capturing energy from sunlight and $\mathrm{CO}_{2}$ and converting it into chemical energy such as complex sugars and $\mathrm{O}_{2}$ that these cells require for basic function (Evans, 2013). Important factors such as plant growth and biomass are directly impacted by both photosynthesis and the process of respiration, which involves the reverse form of photosynthesis but is equally valuable for cell functioning (Evans, 2013). Therefore, it is evident that this type of knowledge could be important for the future of certain agricultural products, where exposure to magnetic fields can create an increase of plant biomass and growth in much more affordable, sustainable, and efficient ways by manipulating different types of biological functions. For example, the germination rate of lettuce seeds under a magnetic field of $1 \mathrm{mT}$ increased in comparison to a control group, altering the osmoregulation of the seeds, allowing faster absorption of water (Reina et al., 2001). The magnetic field was found to be a strong influence, thus increasing the water potential inside the seed, which resulted in effects such as a weakened cell wall that allowed for easier radicle emergence as well as more passive movement of ions and solutes (Reina et al., 2001). 
In the previous study, it is clear through these results that a magnetic field can increase efficiency in terms of certain biological functions of plants. In another example, a study by Esitken \& Turan (2004) examined effects of magnetic fields on yield and nutrient composition of strawberry plants. Plants were exposed to three different magnetic flux densities $(0.096$, 0.192, and $0.384 \mathrm{~T}$ ), along with a control group for several weeks, and different parameters of growth such as fruit yield, fruit number, and weight per plant were measured twice a week. Interestingly, these measured parameters all increased significantly (relative to reference plants) in the plants exposed to a $0.096 \mathrm{~T}$ field. The plants also had much higher composition of nutrients such as potassium, calcium, and nitrogen which are vital for the development and functioning of plants. This study showed that these treatments had significant effects on plant metabolism through hormonal and enzymatic activities such as photosynthesis and synthesis of carbohydrates, where the lower flux densities specifically increased uptake of nutrients towards these synthesis regions (Esitken \& Turan, 2004). It is also suggested through other studies that a stronger magnetic field could be inhibitory, although it is clear through these results that a magnetic field can increase efficiency in terms of certain biological functions of plants.

Changing the orientation of a magnetic field may either inhibit or stimulate biological functions of plants. Audus (1960), found that plants exhibit magnetotropism, where they tend to grow towards the decreasing magnetic field gradient. A study by Turker et al. (2007) examined this where maize and sunflower plants were studied in separate conditions where magnetic fields were parallel and opposite to the directions of gravity. Growth and amounts of chlorophyll were significantly increased in sunflowers in the field-up direction but decreased in the field-down conditions with the same magnetic flux density (15 mT). This shows that 
although all other conditions are the same, the direction of the magnetic field can have either positive or inhibitory effects on biological functions of plants.

Duration of exposure to magnetic fields can also affect plant functioning. A study by

Shine et al. (2011) examined germination, growth, and photosynthesis in soybean plants using magnetic flux densities of 50-300 $\mathrm{mT}$ in 30-, 60-, and 90-minute exposure time blocks. It was found that factors such as water uptake and chlorophyll fluorescence (as a measure of photosynthetic activity) increased during the 60- and 90-minute time blocks in comparison to 30 minutes and the control of no exposure. It was suggested that this occurred due to changes of permeability of the cell membrane to certain ions, as well as alteration of osmotic pressure and other factors that only a longer-duration EMF exposure could cause (Shine et al., 2011). In contrast, in a study by Jan et al. (2015), Lemna minor plants were exposed to different magnetic flux densities (4-100 $\mu \mathrm{T}$ as reference, and $150 \mathrm{mT}$ as treatment) for 7 days straight. Lemna exhibited no significant differences among treatments in photosynthetic rates, again measured as chlorophyll fluorescence. The authors suggested that Lemna may have acclimated to variations in magnetic field over the duration of the experiment, suggesting that exposure time to magnetic fields may be crucial for these types of experiments.

Vashisth \& Joshi (2017) exposed maize seeds to magnetic fields (50, 100, 150, 200, $250 \mathrm{mT}$ ) for different durations (1-4 hours), then planted the seeds and monitored plant growth over 52 days. Chlorophyll concentration, root and shoot biomass was highest in plants that had been exposed as seeds to the $200 \mathrm{mT}, 1$-hour treatment. The authors suggested that these results occurred due to increased internal seed potential or energy along with more calcium ions in the system that allow for important functions such as mitotic division and growth of meristems. Similarly, Shine and Guruprasad (2011) exposed maize seeds to magnetic field 
treatments (100 mT for 2 hours or $200 \mathrm{mT}$ for 1 hour) before planting. Both treatments resulted in a significant increase of chlorophyll in comparison to the control condition, with the $200 \mathrm{mT}$ condition being more effective. Another study looked at the effect of magnetic field on 30-day old Paulownia tissue cultures (Yaycili \& Alikamanoglu, 2005). Tissues were exposed to 2.9$4.8 \mathrm{mT}$ for times of 2.2, 6.6, and 19.8 seconds at a time. Plant height, regeneration ability, and chlorophyll concentrations were significantly higher in response to all magnetic treatment conditions, but were highest in the treatment with longest exposure. The authors suggested the treatment was able to influence metabolism and mitosis in meristematic plant cells, and initiate chemical reactions by affecting electron-spin positions and causing oxygen radical pairs to occur more quickly in water, thus increasing the speed of electron transport within PSII (Hirano et al., 1998; Yaycili \& Alikamanoglu, 2005).

Seasonality may also influence how plants respond to magnetic fields. Novitsky et al. (2001) exposed separate plots of green onion plants to weak permanent magnetic fields with a field flux density of $0.5 \mathrm{mT}$ in spring and summer, respectively. The exposure to magnetic fields in the spring corresponded with increased bulb sprouting and longer leaves, but there were no significant effects of magnetic field exposure in the summer. With higher temperatures being the principle difference between the two seasons, the researchers concluded that higher temperatures had similar reaction targets as the magnetic field, therefore producing confounding effects.

As is evident from the above discussion, there have been contradictory findings on the effects of static (permanent) magnetic field exposure on plants, and few successful replications of studies, although it appears that exposure at a critical stage (near seed germination) may have positive effects on outcomes well into the plant's life cycle. Much of the challenge in 
drawing firm conclusions about effects of magnetic fields stems from differences in parameters measured, plant species studied, magnetic flux densities applied, and duration or seasonality of exposure. More synthesis of past findings and further research with consistent approach is needed to draw any meaningful conclusions that will be of practical use in the agriculture industry.

\subsection{Effects of oscillating electromagnetic fields on plant growth and photosynthesis}

Oscillating electrical current, with a frequency expressed in $\mathrm{Hz}$ or $\mathrm{kHz}$, spawns an orthogonal magnetic field with polarity reversals matching the frequency of the current oscillations. Biological function of plants and other organisms have also been studied under treatment using various oscillating electromagnetic signals (OEMS), such as variations in magnetic field strengths, frequencies, and durations of exposure. In these experiments, treatment must be considered as a combination of electrical field and magnetic field treatment, and biological response cannot be readily ascribed to one field or the other.

One study by Aleman et al. (2014) tested coffee seedlings that were exposed to a $2 \mathrm{mT}$ OEMS that had a frequency of $60 \mathrm{~Hz}$ after the establishment phase. Findings show that rate of net photosynthesis increased significantly with respect to plants in the control condition, and there was also an increase in nutrient absorption, cell metabolism and plant growth. Leaves developed thicker cuticles and an increased abundance in stomata, which would contribute to higher photosynthetic rates. Similarly, sugar beet plants were exposed to an OEMS of $5 \mathrm{mT}$ with a frequency of $16 \mathrm{~Hz}$ from June to September, with the experiment repeated over a 3-year period (Rochalska, 2005). It was found that treated plants had an increase in chlorophyll concentration, as well an increase in nitrogen composition and nutrient uptake. Radhakrishnan 
\& Kumari (2012), exposed soybean seedings to an OEMS of 1500 nT with a frequency of 10 $\mathrm{Hz}$ for 20 days, 5 hours per day. Seedling height, biomass, as well as photosynthetic rate all increased and it was concluded that this occurred due to an increased rate of carbon fixation due to a higher concentration of RuBisCO enzyme. The authors also stated that the treatment caused direct changes in protein and activities of various enzymes, which contributed to increased efficiency in these activities as well as increased uptake of water and minerals as an added contributing factor. Dhawi \& Al-Khayri (2009) compared OEMS with static magnetic fields, where seeds of date palm were placed in conditions where the static magnetic field was 10,50 or $100 \mathrm{mT}$ with six different time conditions, and where OEMS had a magnetic flux density of $1.5 \mathrm{~T}$ with a frequency of $63 \mathrm{kHz}$ and for four different exposure durations. Abundance of photosynthetic pigments were significantly increased under the influence of static magnetic field, but at lower flux densities, a longer exposure was needed to see this effect. In the alternating OEMS, abundance of chlorophyll decreased significantly with exposure durations over 5 minutes. It is difficult to compare magnetic field effects (static versus oscillating) directly, as flux densities were 1-2 orders of magnitude lower in static field treatments versus OEMS treatments. Finally, three very similar studies used the same electromagnetic device and flux densities $(3 \mathrm{~Hz}, 12.5 \mathrm{mT}, 35-80 \times 106 \mathrm{~W})$, to study the effects of OEMS on tomato (Efthimiadou et al, 2014), corn (Bilalis et al, 2012), and wheat (Katsenios et al, 2016). The studies on corn and wheat both demonstrated that OEMS exposure could cause a significant increase in chlorophyll concentration, however the optimal exposure time differed between the two varieties of corn studied (Bilalis et al, 2012), most likely due to minor differences in plant morphology or physiology. The tomato plants exposed to treatment showed no significant differences relative to reference plants in lycopene content, a pigment 
analogous to chlorophyll. The authors suggested that a longer duration of exposure might be needed for tomatoes. The studies reviewed convey that OEMS magnetic field strength and exposure duration may all be important determinants of how a plant responds to treatment. However, the studies cannot separate the potential impacts of magnetic field versus electrical field effects, and treatment using OEMS must be considered in toto. Moreover, the combination of electromagnetic signal and exposure duration that can stimulate plant growth will likely be different from species to species, or even among genetic varieties within a species.

The potential interaction between OEMS exposure and environmental conditions adds a layer of complexity to understanding how a plant will respond. Electromagnetic treatment has been shown to either alleviate harsh effects of other variables, or to produce a confounding effect with these variables, depending on the circumstances. For example, Anand et al. (2011) treated maize seeds with OEMS conditions of 200 and $100 \mathrm{mT}$ (400 W) for 1-2 hour exposure times, and planted the seeds. Stressors such as soil water tension were also manipulated in the study. Treatment enhanced several plant parameters such as leaf chlorophyll content, plant height, and root length, where all values were higher in comparison to the control. Interestingly enough, the treatment also had an interactive effect with soil water tension. The effects of water stress on plant parameters were alleviated in comparison to control plants. The authors suggested that free radical production was restricted under electromagnetic exposure, lowering antioxidant production in plants for their defense systems, meaning that exposed plants were more adaptive to the stressor. Another study by Javed et al. (2011) also looked at maize seeds treated with OEMS at varying fux densities and durations (100 and $150 \mathrm{mT}$, for 5 or 10 minutes) under a drought condition. The results show that although factors such as chlorophyll 
content and growth were drastically reduced by water stress, treatment of seeds alleviated this impact of water stress, particularly when seeds were exposed for 10 minutes. However, although the treatment is able to alleviate some stressors, it is important to acknowledge that there are stressors that create a confounding effect with the OEMS treatment because of similar reaction targets, thus creating an inhibitory or null result of treatment in some cases. As mentioned before, a study by Turker et al. (2007) examined directional (static or permanent field) magnetic field effects on maize and sunflower seeds, and because the field was aligned opposite to gravity for one condition, this suppressed growth, production of chlorophyll, as well as other effects. This is due to a response called magnetotropism, which describes a plant's response to directional magnetic fields that involves growing towards the decrease of a magnetic field gradient (Audus, 1960; Turker et al., 2007). Since both magnetic field and gravitational force affect the same reaction centers (such as mitosis), a confounding effect is produced where there is inhibition of these functions (Audus, 1960; Turker et al., 2007). Such confounding effect of gravity, however, would not be anticipated in the application of OEMS. Lastly, another example of this can be seen by Novitsky et al. (2001), where green onion tissues were grown under a weak permanent magnetic field $(403 \mathrm{~A} / \mathrm{m})$. Two separate experiments were done in the seasons of spring and summer, where it was found that the high temperatures of the summer produced a confounding effect with the magnetic field (Novitsky et al., 2001). This is due to the fact that chlorophyll concentration had no significant difference with the control group during the summer experiment, and magnetic treatment might have the same reaction targets (such as electron transport in the chloroplast) as high temperatures do (Novitksky et al., 2001). As impacts on chlorophyll reaction centres have been proposed for OEMS, as well as for static magnetic fields, then the potential confounding impact of 
temperature may also apply in the application of OEMS treatments. This might be worth further exploration, in the context of crop science research.

\subsection{Effects of oscillating electromagnetic fields on growth and photosynthesis or algae and cyanobacteria}

Lastly, the effects of OEMS on different types of phytoplankton (algae and cyanobacteria) will be discussed. Phytoplankton, which include groups of several autotrophic algae and bacteria, are critical to ecosystems, as they fix most of the organic carbon in many aquatic systems, and serve as the base of the food web. They can also be important for applications such as the cleaning of waste-water (Tu et al., 2015), along with applications such as the creation of biofuels and diesels which are much more sustainable than extracting fossil fuels (Hunt et al., 2009). Therefore, they are important to include in the discussion of OEMS effects on photosynthetic rates, and should likely be the focus of future projects. The studies discussed here demonstrate that electromagnetic fields can enhance photosynthesis and growth of algae and cyanobacteria under certain treatment conditions.

In one study by Hirano et al. (1998), a species of cyanobacteria was cultured and rates of photosynthesis were measured under treatment by an electromagnetic device producing a magnetic field ranging between $0.05-70 \mathrm{mT}$. The peak rate of oxygen evolution occurred between 0.05-10 mT, while growth rate peaked at around 5-35 $\mathrm{mT}$. These results suggest that OEMS signals accelerate the light excitation of chlorophyll, the production of radical pairs and electron transfer, and even possibly the increase of surface area of thylakoids, which allows more exposure to $\mathrm{CO}_{2}$ fixing molecules (Hirano et al., 1998). This in turn allowed for an 
increase in the conversion of light energy to chemical energy, thus increasing biomass production along with the rate of photosynthesis. However, it is important to note that any value above $40 \mathrm{mT}$ produced an inhibitory effect on these types of functions, where protein structures started to become damaged and reactions slowed down.

In another experiment by Tu et al. (2015), Scenedesmus obliquus (a species of green microalgae) was cultivated in municipal wastewater and exposed to OEMS with magnetic field strength of 50-500 $\mathrm{mT}$, and oxygen production and chlorophyll content were measured. There were also four different types of experimental setups, which included a control (no treatment), treatment in early cultivation, treatment throughout the study, and treatment only in the log phase of growth. Results show that chlorophyll-a content was higher in the treatments where treatment was continual, or where treatment occurred in the log phase of growth. Optimal primary production occurred when magnetic field strength was below $100 \mathrm{mT}$, where the treatment enhanced the electron transfer pathway and enzyme speed. Flux densities above this resulted in changes in enzyme conformations that affected these pathways negatively. Tu et al. (2015) suggested that use of OEMS to enhance oxygen production could be an efficient, lowcost technology to enhance the operation of sewage-microalgae systems for cleaning.

Another study examined the rate of carbon fixation by Chlorella fusca (Deamici et al., 2018). The conditions included a control, and a treatment receiving an electromagnetic signal with magnetic field strength at either $30 \mathrm{mT}$ or $60 \mathrm{mT}$, applied for either one hour a day, or for 24 hours per day. Although all treatments receiving an electromagnetic signal saw a significant increase in carbon fixation and growth, the optimal treatment was where field strength was 60 $\mathrm{mT}$ for just one hour a day exposure. The authors suggested that Chlorella fusca likely showed 
an acclimative or stress response under constant treatment, and may have accordingly reduced carbon fixation relative to the shorter duration exposure.

Li et al. (2006) studied growth of Spirulina platensis in a photobioreactor with treatment ranging from $0-0.55 \mathrm{~T}$ with continual exposure to the electromagnetic signal for 9 days. Optimal growth peak occurred where magnetic field strength was $0.25 \mathrm{~T}$, while exposure to flux densities above 0.4 T inhibited growth. Finally, Small et al. (2012) saw nearly a fourfold increase in biomass and lipid content in Chlorella kessleri with a flux density of $10 \mathrm{mT}$.

\subsection{Rationale for Selection of Photosynthetic Organisms}

There are many different types of organisms that can exist within the three domains of life, which include the Bacteria, Archaea, and Eukarya (Waldbauer et al., 2009). Within these domains of life, some organisms have the ability to perform photosynthesis which branch off into smaller groups such as higher plants and algae that are found within Eukarya, and cyanobacteria which are found within Bacteria (Waldbauer et al., 2009). Differences between the groups of Eukarya and Bacteria lie within the internal parts of the cells, where Eukarya have membrane bound organelles, and bacteria tend to lack these components. Although this provides several options for organism selection, it was necessary for this specific study that the selected photosynthetic organisms were unicellular phytoplankton that are commonly studied and found in freshwater systems (Waldbauer et al., 2009). These criteria were established so that the study would be able to use simpler organisms that have a large amount of researched data about them available (particularly about photosynthesis), and that it could be applicable to several other future studies as well. This previous research could also aid in examining and comparing factors such as growth curves, which would allow for informed and successful 
progression of experiments. Furthermore, it was also desired that these species would help broadly encompass three main groups of phytoplankton (green algae, cyanobacteria, and diatoms) found in freshwater systems, as they are all very critical for the functioning of freshwater communities, and can be further applied to community based future studies that could include mesocosms and smaller ecosystems. Despite this, it is also valuable to look at these three types of phytoplankton on an individual level, where each type has valuable or critical contribution to freshwater systems. For example, although all three types have a valuable role in food webs and biogeochemical cycles, diatoms are responsible for a significant amount of $\mathrm{CO}_{2}$ uptake, and cyanobacteria are usually responsible for detrimental algal blooms that can lead to several negative impacts.

Therefore, with these criteria in mind, Chlorella vulgaris, Microcystis aeruginosa, and Cyclotella pseudostelligera were all selected for this study on the basis that they are all common freshwater photosynthetic microorganisms that account for selection from green algae, cyanobacteria and diatoms, and they are easily obtained and cultured with well-known characteristics found within previous studies.

\subsection{Objectives}

Electromagnetic treatment has the potential to affect growth and photosynthesis in plants, algae, and cyanobacteria. Treatment could be beneficial in increased efficiency in agricultural industries, the production of biofuels and biodiesels, as well as restoration of water bodies. However, with respect to algal species in particular, much more research needs to be done before these applications can be used. In treatments using OEMS, it is unclear whether 
the effects on biological processes are the result of magnetic fields, electrical fields, or both. Because effects on some of these same biological processes have been reported under static magnetic field treatment, it is likely that the magnetic field is an important contributor. However, the response to OEMS treatment must be considered as a response to the combination of electrical and magnetic fields. As such, it may be more relevant, at present, to consider response to OEMS in relation to power (Watts) necessary to generate these fields.

In algae and cyanobacteria, the stimulatory effects of treatments on growth and photosynthesis generally occurred in the range of single-digit to low tens of W. However, with the exception of Hirano et al. (1998) who applied magnetic field flux densities as low as $5 \mathrm{~W}$, there is very little knowledge of how very low-powered electromagnetic treatment devices, under conditions of chronic exposure, will affect growth of algae and cyanobacteria. Treatment using lower power (and hence, energy input), would be beneficial in large-scale application of OEMS treatment.

The objective of this specific study is to determine if:

1) EMF treatment with very low power $(<10 \mathrm{~W})$ can affect the growth and/or metabolic activity of algae and cyanobacteria

Leading to additional questions which include:

Will there be differences among different types of photosynthetic microorganisms?

Are there possible future applications such as the control/regulation of growth of phytoplankton?

It can be hypothesized that there will be differences among different types of photosynthetic organisms with possible applications in the control/regulation of growth of said 
organisms. Addressing these objectives will help improve the current understanding of how OEMS may affect growth of algae in aquatic systems, and perhaps how treatment might affect relative abundance of different algae in mixed communities. This understanding will hopefully result in broader application of these types of studies with a wider range of algal species as well as deployment of experiments in a field-based setting.

\section{Methods}

\subsection{Organisms}

\subsubsection{Selected Organisms and Rationale}

Chlorella vulgaris, Microcystis aeruginosa, and Cyclotella pseudostelligera were all selected for this study on the basis that they are all common freshwater photosynthetic microorganisms that are easily obtained and cultured. It was also desired that three of the main groups of phytoplankton (green algae, cyanobacteria, and diatoms) would be included so that this study would have a broader application in freshwater systems and communities.

\subsubsection{Culturing Conditions for Organisms}

C. vulgaris and M. aeruginosa were both obtained from Carolina Biological Supply (Burlington, NC) and were cultured in Bristol's media as per the Ontario Ministry of Environment Guidelines (Poirier et al., 1988) (Appendix I), while C. pseudotelligera was obtained from the Scottish Marine Institute and cultured in WC media (Guillard \& Lorenzo, 
1972) (Appendix I). The $C$. vulgaris and $C$. pseudotelligera were aerated during growth using bubblers to introduce filtered air (Whatman Grade GF/F filters, nominal pore size $0.7 \mu \mathrm{m}$ ) through aquarium tubing with short lengths of glass tube fitted at the ends for extra weight (to introduce the bubbles at the bottom of each flask). M. aeruginosa was not aerated, but each culture flask was swirled a few times each day. Flasks were placed under XTRABRITE VITALUX continuous lighting with a room temperature of $22^{\circ} \mathrm{C} \pm 1$. After suitable growth was confirmed by direct cell counts using a haemocytometer, stock cultures were used to inoculate the jars that served as replicate units for the experiment.

\subsection{Experimental Setup}

\subsubsection{Physical set-up}

A total of 9 glass jars $(10 \mathrm{~cm}$ diameter, each with a volume of $1.5 \mathrm{~L})$ were used in each experiment to test effects of electromagnetic fields on a given photosynthetic microorganism.

Within each experiment, three jars served as replicates for each OEMS treatment (Figure 2.1). The three different treatments included control (no signal applied), application of signal 1, and application of signal 2. Signal 1 and signal 2 are proprietary signals, differing in power used to generate the electromagnetic fields, but each below $10 \mathrm{~W}$ ). Treatment was randomized with respect to individual jars. A transducer was installed into each jar receiving an OEMS treatment. These signals selected were based on previous studies on effects of treatment on gas flux, acknowledging that a signal which impacts gas transfer may be different than a signal which impacts phytoplankton growth. 


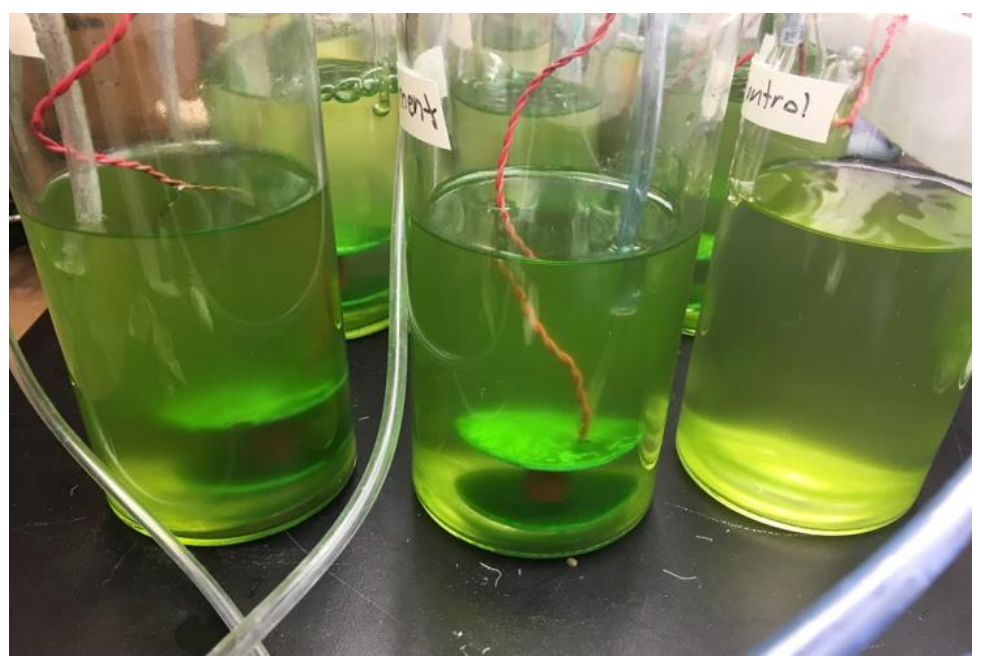

Figure 2.1 Image of 3 out of the 9 total jars used as replicate experimental units; two jars on left each contain a transducer, jar on right is a reference replicate

Jars were filled with 1L of growth media, either Bristol's (for Chlorella or Microcystis experiments) or WC media (for the Cyclotella experiment). Jars and media were autoclaved for 20 minutes at $121^{\circ} \mathrm{C}$. WC media was filtered using Whatman Grade GF/B glass microfiber filters (with a pore size of $0.5 \mu \mathrm{m}$ ) before autoclaving to remove precipitates. After cooling, these jars were fitted with bubblers (rinsed in $70 \%$ ethanol prior to experiment), and aerated using filtered air, as above, in experiments using Chlorella and Cyclotella (Microcystis did not require aeration). Jars were inoculated from stock culture, placed under cool white fluorescent lights with continuous illumination as described above, and incubated at room temperature of $22^{\circ} \mathrm{C} \pm 1$. After set up, the transducers were activated. OEMS exposure was continuous for the jars receiving signal 1 or signal 2. 


\subsection{Experimental Runs}

\subsubsection{Measuring Biomass}

Biomass measurements were made every day at the same time by pipetting a sample of the culture from each jar into a haemocytometer under a microscope (Figure 2.2). Two small grids within each of the nine large grids were selected by using a random number generator and were counted, for a total of 18 counted grids. Since conversions to number of cells mL-1 are normally done using 16 grids, the count was normalized and converted to number of cells mL-1 by using this formula:

cells counted $\times(16 / 18) \times 10000=$ cells $\mathrm{mL}-1$

(eq. 1)

These cell counts were used to plot separate growth curves for every jar, for a total of 9 days. By 9 days, the cell densities reached a plateau and, in some cases, began to decrease, indicating the onset of senescence.

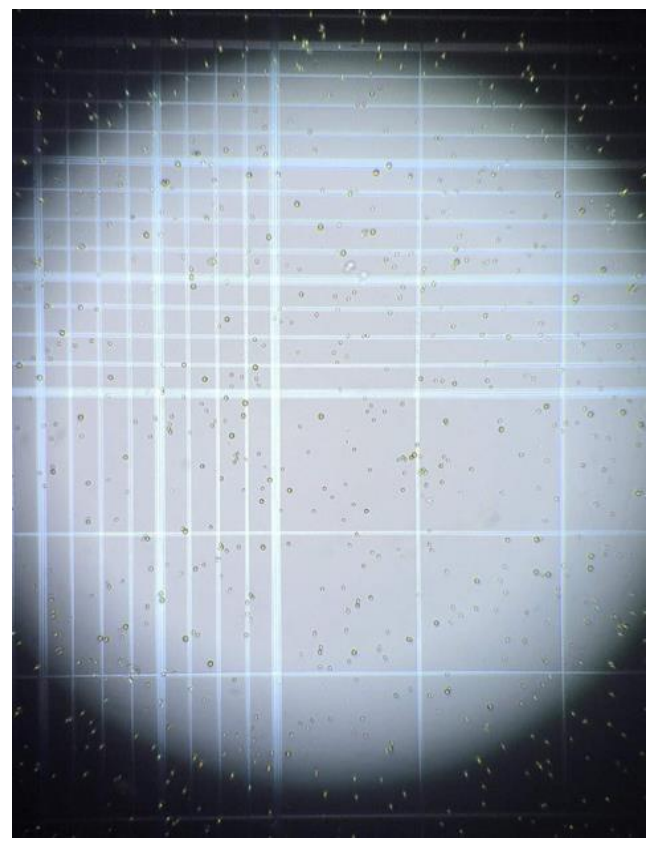




\section{Figure 2.2 Chlorella vulgaris cells under the microscope in the haemocytometer}

\subsubsection{Measuring Photosynthetic and Respiration Rates}

Photosynthetic and respiration measurements were done at the same time every day by transferring an $8 \mathrm{~mL}$ sample from each jar into a $14 \mathrm{~mL}$ Falcon ${ }^{\circledR}$ tube, and placing it in a test tube rack beside a cool white fluorescent light (Figure 2.3). A Clark-style oxygen microsensor, connected to a Picoammeter 2000 (both from Unisense A/S, Aarhus, Denmark), was placed into the tube with the light on. The picoammeter was also connected to a Unisense ADC216 USB logger, which was connected to a computer operating a program called Unisense Logger that logged the signal from the oxygen sensor in units of millivolts $(\mathrm{mV})$ every 15 seconds. For each sample, the light was kept on for the first two minutes to ensure that the probe was equilibrated to the oxygen concentration in the sample. It was then turned off for 10 minutes to measure the rate of decline in oxygen during this time (recorded in $\mathrm{mV}$ ). The light was then turned on for 5 minutes to measure the rate of increase in oxygen. Values recorded in $\mathrm{mV}$ were converted to values of $\mu \mathrm{mol} \mathrm{O}_{2} / \mathrm{L}$ using the formula:

$$
((\mathrm{X} \mathrm{mV}-43.68 \mathrm{mV}) /(832.48 \mathrm{mV}-43.68 \mathrm{mV})) \times 267.25 \mu \mathrm{mol} \mathrm{O} / \mathrm{L}
$$

Where $\mathrm{X}$ represents the recorded output from the picoammeter at any given time, 43.68 represents the $\mathrm{mV}$ recorded when the probe is in an anoxic solution containing the oxygen scavenger sodium thiosulfite, 832.48 represents $\mathrm{mV}$ recorded when the probe was in water equilibrated with the atmosphere at $22^{\circ} \mathrm{C}$ (i.e. $100 \%$ oxygen saturation), and $267.25 \mu \mathrm{mol} \mathrm{O} / \mathrm{L}$ is the equilibrium oxygen concentration at $22^{\circ} \mathrm{C}$ (Weiss, 1970). 


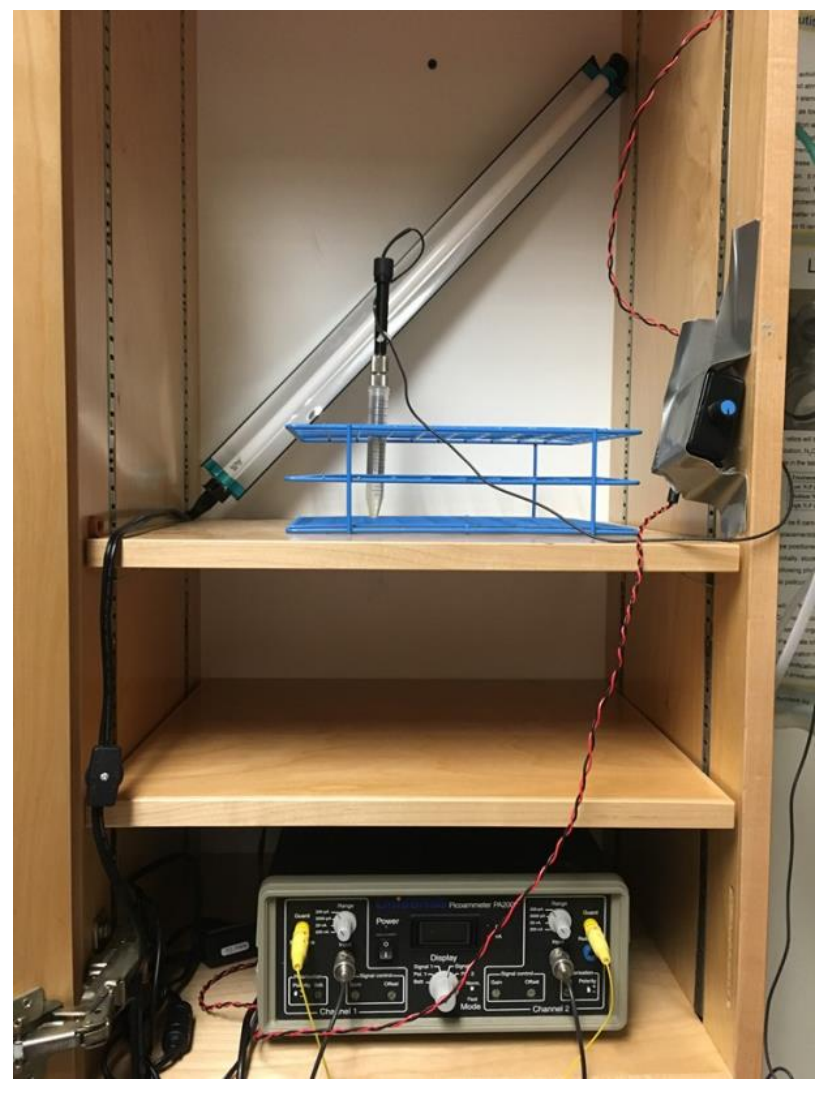

Figure 2.3 Experimental setup used for measuring respiration and photosynthetic rates of cell samples

Once the picoammeter recordings were converted to oxygen concentrations using the above equation, the values from days 5, 7, and 9 were plotted as scatter plots graphs in Excel, separating the dark measurements from light measurements for each sample onto individual plots. Trendlines (linear) were fitted and slopes represented rates of respiration (for the dark time series and decrease in oxygen), net production (for the light time series and increase in oxygen), and gross production (sum of respiration and net primary production rates).

Respiration, net production, and gross production rates were then normalized to biomass for each day to determine the average rate per 106 cells. 


\subsubsection{Modeling growth}

Intrinsic growth rates and maximum cell density were modeled from cell count data using SigmaPlot 13 (Systat Software, Inc., San Jose, CA) for each experimental unit (jar) for all three species of phytoplankton, fitting data to the integrated form of the logistic growth curve:

$$
N_{t}=\frac{K}{1+\left(\frac{K}{N_{0}}-1\right) e^{r t}}
$$

Where $\mathrm{K}$ is the maximum cell density, $\mathrm{r}$ represents the maximum intrinsic growth rate, $\mathrm{N}_{\mathrm{t}}$ is the cell density at any given time $(\mathrm{t})$ and $\mathrm{N}_{0}$ is the initial cell density on day 1 of the experiment.

\subsection{Statistical Analyses}

Maximum cell density and intrinsic growth rates were compared among treatments using non-parametric Kruskal-Wallis tests using SAS Enterprise Guide (version 7.1, SAS Institute, Inc., Cary, NC). Kruskal-Wallis tests were used rather than one-way ANOVA as the residuals analysis in initial ANOVA models suggested data did not conform to assumptions of parametric tests (equality of variance, normal distribution) and data transformation did not improve the data fit to parametric models. Biomass-normalized respiration, net production, and gross production rates were compared among treatments using one-way ANOVA (SAS Enterprise Guide v7.1). For analyses using ANOVA, an a priori $\alpha$ of 0.05 was adopted. Where a significant treatment effect was identified, a Tukey's post hoc test was employed to determine pairwise differences among treatments. As statistical power is relatively poor with a 
Kruskal-Wallis test using three replicates, an a priori $\alpha$ of 0.10 was adopted. As there is not an equivalent post hoc, non-parametric paired comparisons test available in SAS Enterprise, post hoc comparisons were made between treatments using Kruskal-Wallis, including only the pair of treatments of interest (i.e. signal 1 vs. reference or signal 2 vs. reference).

\section{Results and Discussion}

\subsection{Growth Rates and Maximum Density}

For Microcystis aeruginosa, Signal 1 resulted in a significant increase in growth rate, in relative to the reference $\left(\chi_{2}=3.86, \mathrm{p}=0.0495\right)$. Both Signal $1\left(\chi_{2}=3.86, \mathrm{p}=0.0495\right)$ and Signal 2 $\left(\chi_{2}=3.86, \mathrm{p}=0.0495\right)$ resulted in a significant increase in maximum cell density relative to reference (Table 3.1).

\begin{tabular}{|c|c|c|c|c|c|c|}
\hline & \multicolumn{2}{|c|}{ Microcystis aeruginosa } & \multicolumn{2}{|c|}{ Cyclotella pseudostelligera } & \multicolumn{2}{|c|}{ Chlorella vulgaris } \\
\hline Treatment & $\begin{array}{l}\text { growth rate } \\
(105 \text { cells d-1) }\end{array}$ & $\begin{array}{l}\text { max density } \\
(105 \text { cells })\end{array}$ & $\begin{array}{l}\text { growth rate } \\
(105 \text { cells d-1) }\end{array}$ & $\begin{array}{l}\text { max density } \\
(105 \text { cells })\end{array}$ & $\begin{array}{l}\text { growth rate } \\
(105 \text { cells d-1 })\end{array}$ & $\begin{array}{l}\text { max density } \\
(105 \text { cells })\end{array}$ \\
\hline Reference & $0.48 \pm 0.10$ & $9.26 \pm 0.94$ & $3.9 \pm 2.95$ & $38.4 \pm 18.4$ & $2.04 \pm 0.52$ & $10.6 \pm 3.4$ \\
\hline Signal 1 & $0.80 \pm 0.24 *$ & $29.7 \pm 4.80^{*}$ & $3.33 \pm 11.89$ & $17.0 \pm 4.57 *$ & $1.35 \pm 0.14^{*}$ & $18.6 \pm 5.6^{*}$ \\
\hline Signal 2 & $0.45 \pm 0.37$ & $22.3 \pm 8.6^{*}$ & $2.32 \pm 1.68$ & $35.4 \pm 8.4$ & $1.24 \pm 0.34 *$ & $20.8 \pm 5.46^{*}$ \\
\hline
\end{tabular}

Table 3.1 Mean \pm standard deviation growth rates and cell yields across different electromagnetic field conditions for Chlorella vulgaris, Microcystis aeruginosa, and Cyclotella pseudostelligera.

In Cyclotella pseudostelligera, Signal 1 resulted in a significant decrease in maximum cell density, relative to the reference $\left(\chi_{2}=3.86, \mathrm{p}=0.0495\right)$. Growth rates tended to be lower under both signals, although the decreases in growth rates were not statistically significant. 
Both Signal $1\left(\chi_{2}=3.86, \mathrm{p}=0.0495\right)$ and Signal $2\left(\chi_{2}=3.86, \mathrm{p}=0.0495\right)$ resulted in a significant decrease in growth rate of Chlorella vulgaris, relative to the reference. Interestingly, both Signal $1\left(\chi_{2}=3.86, \mathrm{p}=0.0495\right)$ and Signal $2\left(\chi_{2}=3.86, \mathrm{p}=0.0495\right)$ resulted in a significant increase in maximum cell densities relative to the reference. So, while the algae grew more slowly, they ultimately reached a greater biomass.

\subsection{Photosynthetic Rates}

Because net production rates are directly correlated with growth rates, and given that net production is better captured by change in cell densities day by day (oxygen production was measured only 3 times over the experiment), net and gross production results are not discussed here, although the data are available in Appendix II. Respiration rates were further examined and displayed due to their own significant metabolic roles such as carbon and energy regulation and lack of correlation with these other processes.

\subsubsection{Respiration Rates of Microcystis aeruginosa}

Respiration rates, measured as oxygen consumption per unit time, are included in the discussion here as respiration captures information on how much energy is being consumed per unit biomass. Cultures under two different treatments might, for example, have similar net production rates, but differ in respiration rates. This would suggest that the treatment with higher respiration rate requires more energy to maintain growth (i.e. is growing less efficiently). Respiration rate measurements of $M$. aeruginosa were made on days 5, 7, and 9 of the experiment (Figure 3.1). For the respiration rate per 104 cells in M. aeruginosa, there is no 
statistically significant effect of the electromagnetic treatments on the respiration rate (ANOVA, $\mathrm{f}=0.78, \mathrm{p}=0.4655)$. However, respiration rates under OEMS treatments were lower than in reference samples on all days, particularly on days 5 and 7 , and when these days were compared separately, there is a marginally significant treatment affect (ANOVA, $\mathrm{f}=2.76, \mathrm{p}=$ 0.0953). Therefore, the respiration results, combined with growth data, suggest that $M$. aeruginosa grew more efficiently under both OEMS treatment conditions than under reference conditions, which indicates that the treatment conditions possibly had a significant effect.

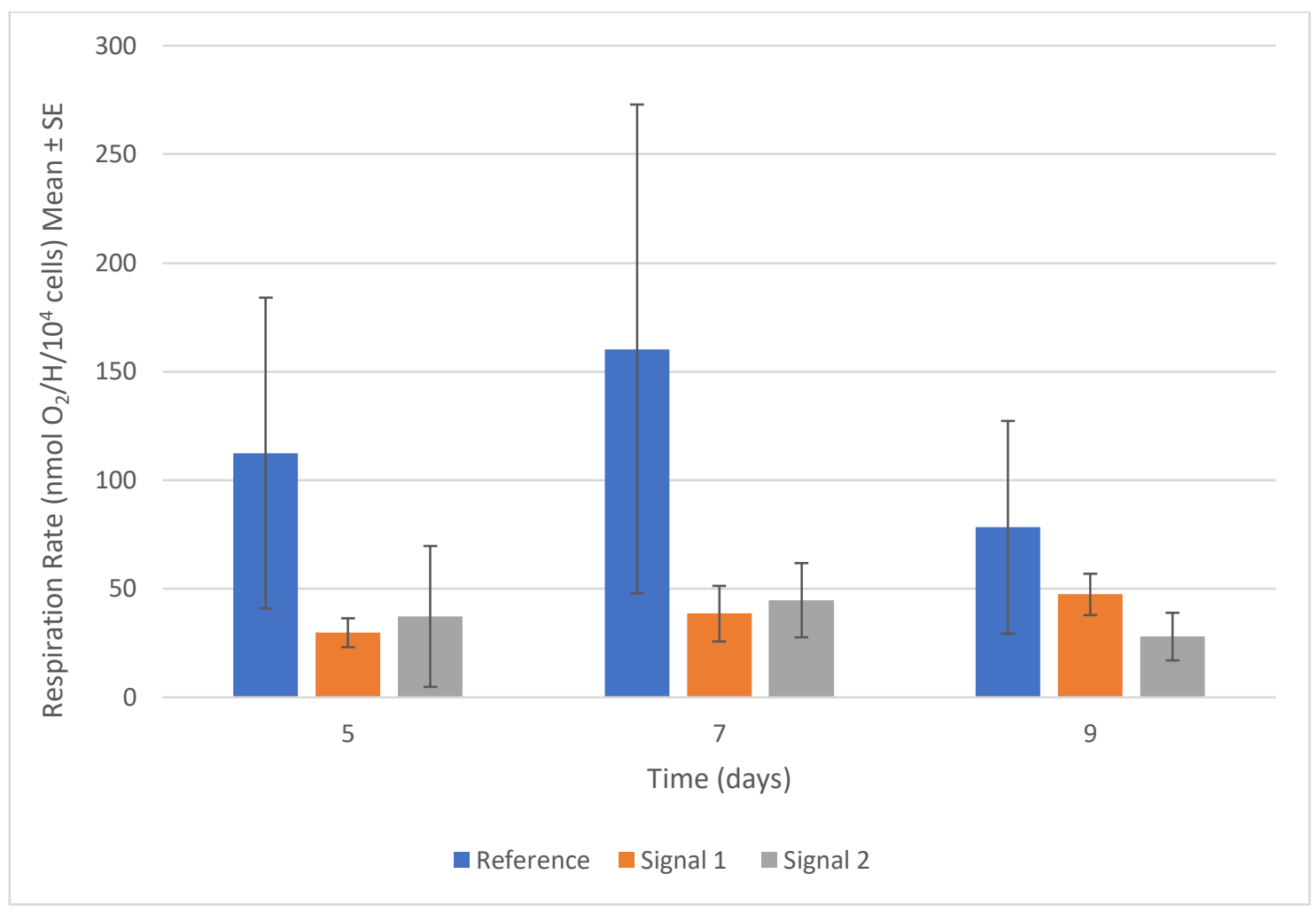

Fig. 3.1 M. aeruginosa mean \pm standard error respiration rates over time across different electromagnetic field conditions 


\subsubsection{Respiration Rates of Cyclotella pseudostelligera}

Respiration rate measurements of C. pseudostelligera were made on days 5, 7, and 9 of the experiment (Figure 3.2). For the respiration rate per 104 cells in C. pseudostelligera, there was a strong significant effect of treatment overall (ANOVA, $f=4.05, p=0.0267$ ), especially early in the growth phase (as indicated on day 5), where there was a higher respiration rate for cells under OEMS treatment. This suggests that treatment may have created some metabolic stress for the diatom, indicated by the higher respiration levels in the first two days, thus reducing its growth efficiency, which may help explain why signal 1 resulted in lower maximum cell density. The decreased respiration levels in day 9 may indicate an adaptive response within the cells, where metabolic stress may have decreased over time.

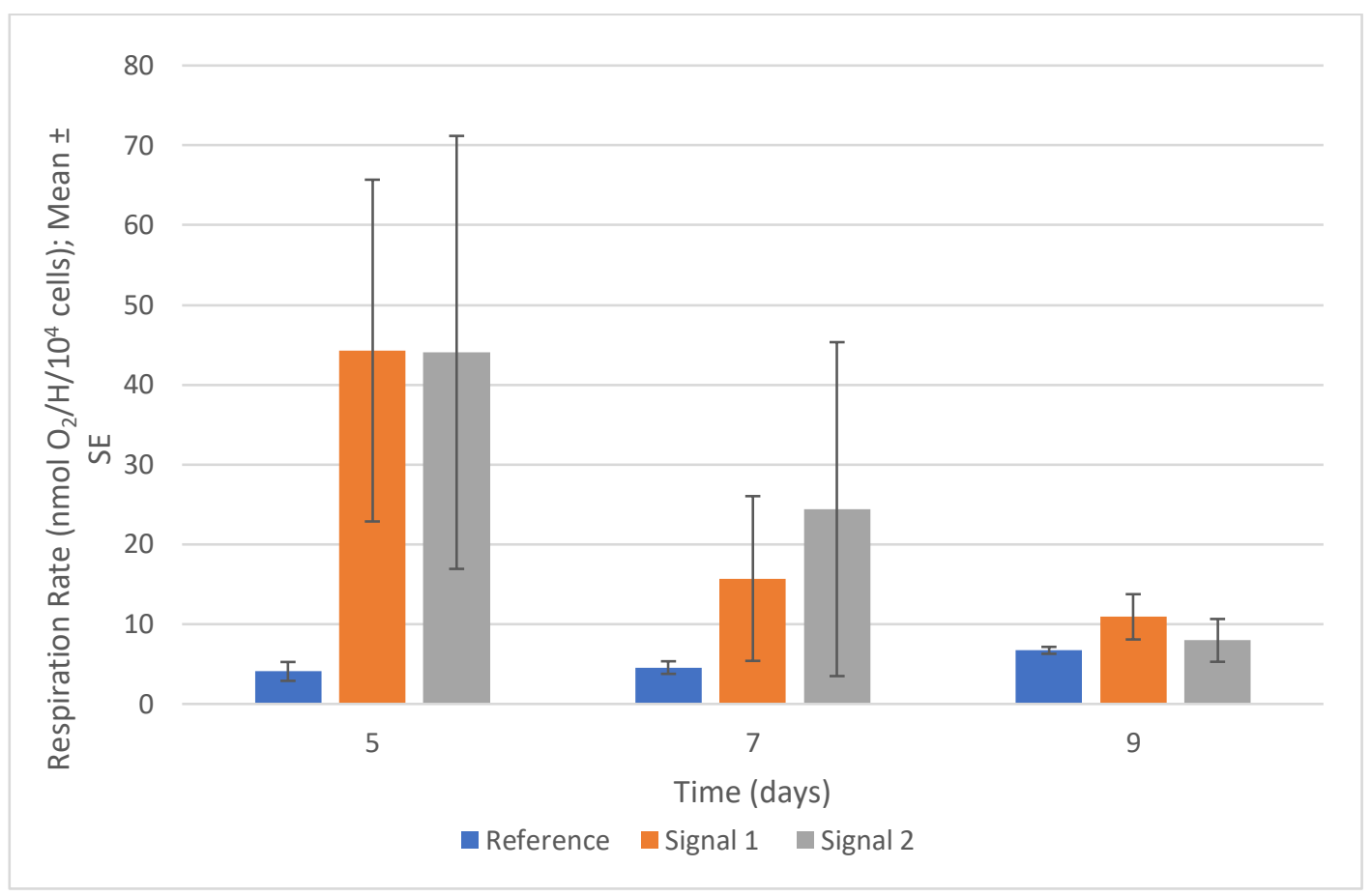


Fig. 3.2 C. pseudostelligera mean \pm standard error respiration rates over time across different electromagnetic field conditions.

\subsubsection{Respiration Rates of Chlorella vulgaris}

Respiration rate measurements of C. vulgaris were made on days 5, 7, and 9 of the experiment (Figure 3.3). For the respiration rate per 104 cells in C. vulgaris, there was no overall significant effect of treatment on the respiration rate (ANOVA, $f=0.48, p=0.6219$ ), however, respiration rates per unit biomass were initially similar among treatments (day 5), but later in the experiment, respiration increased under reference conditions, and decreased under OEMS treatment. By days 7 and 9 treatment resulted in a significantly lower respiration rate relative to reference (ANOVA, $\mathrm{f}=8.23 \mathrm{p}=0.0039$ ), where this change in biomass-normalized respiration over time could account for the higher maximum cell density associated with OEMS treatment, as efficiency of carbon assimilation diverged over time among treatments. 


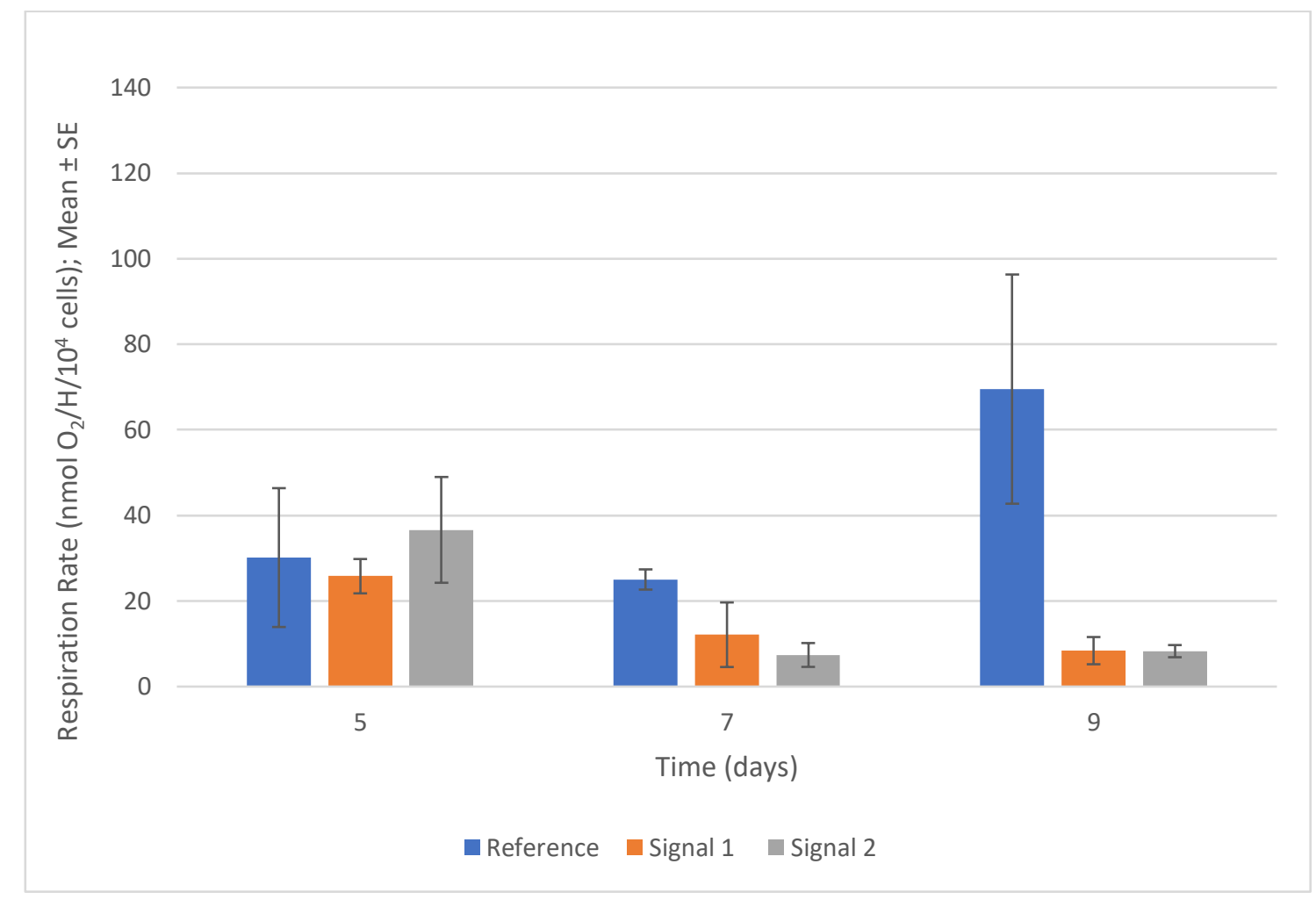

Fig. 3.3 C. vulgaris mean \pm standard error respiration rates over time across different electromagnetic field conditions

\subsection{Revisiting effects on Growth Rate, Maximum Cell Densities, and Photosynthesis of Three Phytoplankton Species}

These results support several other similar studies that were done with similar green algae species and electromagnetic fields where growth and photosynthesis were both increased. For example, in a study by Deamici et al. (2018), it was found that Chlorella fusca grown in a cylinder that was constantly pumped with $\mathrm{CO}_{2}$, had increased growth and photosynthesis under OEMS treatment. Another study using Chlorella kessleri found that a static magnetic field of $10 \mathrm{mT}$ had also increased cell yield by about fourfold, and net photosynthetic rate by two-fold (Small et al., 2012). Lastly, another study that was done with Scenendesmus obliquus (another 
species of green algae), also had results where growth, chlorophyll concentration, and oxygen production (conversely with oxygen consumption) were all increased under treatment using OEMS (Tu et al., 2015). All of these studies suggested that these effects occurred because the electromagnetic fields stimulate electron excitation in the electron transport chains found in chlorophyll, as well as enzyme speed, thus making the chemical processes faster and efficient (Deamici et al., 2015; Small et al., 2012; Tu et al., 2015). They had also suggested that water and nutrient uptake efficiency was increased due to the cell membrane becoming more permeable, where the electromagnetic field could have changed the cell membrane and water composition (such as increased $\mathrm{O}_{2}$ solubility), resulting in this effect (Deamici et al., 2015; Small et al., 2012; Tu et al., 2015). In this experiment, although $C$. vulgaris experienced slower growth under OEMS treatment, maximum cell densities were greater under treatment conditions, likely because carbon assimilation efficiency increased under treatment and decreased under reference conditions over time (as density increased). Nutrient uptake efficiency may also have increased under OEMS treatment, perhaps due to cell membrane and water composition changes. Further studies would need to be done in order to closely examine the integrity of the cell structures of $C$. vulgaris after exposure to OEMS, as well as to examine differences in nutrient uptake efficiencies under treatment and reference conditions.

Hirano et al. (1998) demonstrated that cyanobacteria (Spirulina platensis), like green algae, could also be stimulated by OEMS treatment, with higher growth and photosynthetic rates under certain treatment conditions. Consistent with that observation, in the current study M. aeruginosa was stimulated by OEMS. Signal 1 caused an increased growth rate, and both signal conditions resulted in higher maximum cell densities in comparison to the reference. 
Response to OEMS is not monotonic in cyanobacteria and green algae, as demonstrated by Hirano et al. (1998) using Spirulina platensis and by Tu et al. (2015) with the Scenendesmus obliquus. In each of the studies, while a relatively low-power signal stimulated growth, more powerful signals had negative impacts on growth and photosynthesis. Authors of both studies suggest that at more powerful OEMS signals, the electron transfer pathways as well as enzymes either change conformations or the structures themselves are mostly or completely destroyed, thus unable to properly function, resulting in slower growth rates (Hirano et al., 1998; Tu et al., 2015).

In contrast to the stimulation observed for M. aeruginosa and $C$. vulgaris in response to OEMS, C. pseudostelligera was negatively affected, with generally lower growth rates and maximum cell densities. Diatoms might have a greater challenge in obtaining and using nutrients under OEMS treatment conditions. The difference responses observed among phytoplankton species, including the negative responses of diatoms, may be related to differences in physiology or charge environments around the cell walls (or frustule, in the case of $C$. pseudostelligera). In a study done by Hadjoudja et al. (2009), cell surfaces of $C$. vulgaris and $M$. aeruginosa were examined and compared, and it was found that the cell surface of $M$. aeruginosa was less hydrophobic and had a less negative surface charge over a larger $\mathrm{pH}$ range along with more present carboxyl groups when compared to C. vulgaris (Hadjoudja, 2009). Most diatom species have a near-neutral $\mathrm{pH}$ around their cell membrane frustule structures, but this tends to increase when there is photosynthetic removal of carbon (which occurs throughout respiration) to a more basic $\mathrm{pH}$ (Kuhn \& Kohler-Rink, 2008). The surface charge of diatoms tends to be more negative than that of cyanobacteria and green algae. Charged particles, including ionic forms of inorganic nitrogen and phosphorus, may interact differently with the 
membranes of $C$. vulgaris, $M$. aeruginosa and C. pseudostelligera based on hydrophobicity and charge. Application of electromagnetic fields may further modulate how the nutrients interact with the fields themselves, and with the cell membranes. A gap in current understanding is how OEMS treatment may affect the charge environment at cell surfaces, which could be important in determining relative nutrient capture efficiencies under treatment conditions.

\section{Conclusion}

In conclusion, this study examined three phytoplankton species under reference conditions, and under two different OEMS conditions. These types of conditions were used to examine how common phytoplankton species respond to these types of effects. The results show that there are several significant effects that occurred, which differed between each species.

Therefore, EMF with very low power did affect the growth and/or metabolic activity of algae and cyanobacteria, and there were differences among the different types of photosynthetic organisms that were studied. Lastly, with this knowledge, there could be possible future applications such as the control/regulation of growth of phytoplankton.

These effects need to be further studied in order to explore what exactly they mean on the cellular level as well as for broader applications. Implications of this could include changes in community composition if similar treatment conditions were deployed in a pond environment as an example, where if an ideal OEMS range is used, the competitive balance can be tipped towards specific types of organisms that would benefit the overall functioning of said environment. This could include using a more ideal OEMS range to benefit species such as $C$. pseudostelligera, which is responsible for carbon uptake while playing an important role as a 
primary producer within several ecosystems. In turn, tipping this competitive scale could reduce abundance of species such as $M$. aeruginosa, which can contribute to a lot of algal bloom problems, but with the help of a specific OEMS range, as well as increased direct competition from other species such as $C$. pseudostelligera, its numbers can be kept in control and an ideal pond ecosystem can be achieved. To accomplish this, future studies can test these electromagnetic field effects on mixed cultures, as well as further modifying the OEMS ranges to see if different results can be acquired. Other suggestions for future studies include examining intracellular structures, specifically those used for photosynthetic functions, and charge environments on cell membranes to see what is exactly causing these effects on the cellular level. An example of this would be examining differences within the chloroplast and its components such as the thylakoid structures and the photosynthetic centers that are found within them, where this can be done through methods such as sonication and UV spectrometry. Furthermore, cell membrane structures and proteins such as the ion channel pathways and transmembrane enzymes respectively can be examined and have their activity levels quantified and compared through similar methodologies. This is especially valuable, as examining these differences in structures could help the design of targeted OEMS treatments that would encourage or discourage functions such as growth rates based on the ecosystem's needs. Again, this leads up to potentially reducing problems such as algal blooms that occur in many of these environments. Lastly, an interesting idea for future studies would include using the treatments on a broader scale application such as a mesocosm setting to examine what would happen in a more natural-based environment. 


\section{Appendix I \\ Media used for Algal Growth}

Bristol Media (Poirier et al., 1988) based on the Ontario Ministry of the Environment, this was used for the culturing and growth of Chlorella vulgaris and Microcystis aeruginosa.

Add $10 \mathrm{ml}$ of each of the following stock solutions to $940 \mathrm{ml}$ of distilled water (macronutrients):

$\begin{array}{lc}\text { Solution } & \text { Concentration } \\ \mathrm{NaNO}_{3} & 25.0 \mathrm{~g} / \mathrm{L} \\ \mathrm{CaCl}_{2} .2 \mathrm{H}_{2} \mathrm{O} & 2.5 \mathrm{~g} / \mathrm{L} \\ \mathrm{MgSO}_{4} .7 \mathrm{H}_{2} \mathrm{O} & 7.5 \mathrm{~g} / \mathrm{L} \\ \mathrm{K}_{2} \mathrm{HPO}_{4} & 7.5 \mathrm{~g} / \mathrm{L} \\ \mathrm{KH}_{2} \mathrm{PO}_{4} & 17.5 \mathrm{~g} / \mathrm{L} \\ \mathrm{NaCl} & 2.5 \mathrm{~g} / \mathrm{L}\end{array}$

Add $1.0 \mathrm{ml}$ of each of the following stock solutions (minor nutrients) to the litre solution above:

$\begin{array}{ll}\text { EDTA }-\mathrm{Na}_{2} & 50.0 \mathrm{~g} / \mathrm{L} \\ \mathrm{KOH} & 31.0 \mathrm{~g} / \mathrm{L} \\ \mathrm{FeCl}_{3} .6 \mathrm{H}_{2} \mathrm{O} & 4.84 \mathrm{~g} / \mathrm{L}+1 \mathrm{ml} \mathrm{H} 2 \mathrm{SO} 4 \\ \mathrm{H}_{3} \mathrm{BO}_{3} & 11.42 \mathrm{~g} / \mathrm{L}\end{array}$

Micronutrient solution:

$\begin{array}{lc}\mathrm{MnCl}_{2} .4 \mathrm{H}_{2} \mathrm{O} & 1.44 \mathrm{~g} / \mathrm{L} \\ \mathrm{ZnSO}_{4} .7 \mathrm{H}_{2} \mathrm{O} & 8.82 \mathrm{~g} / \mathrm{L} \\ \mathrm{MoO}_{3} & 0.71 \mathrm{~g} / \mathrm{L} \\ \mathrm{CuSO}_{4} .5 \mathrm{H}_{2} \mathrm{O} & 1.57 \mathrm{~g} / \mathrm{L} \\ \mathrm{Co}\left(\mathrm{NO}_{3}\right)_{2} .6 \mathrm{H}_{2} \mathrm{O} & 0.49 \mathrm{~g} / \mathrm{L} \\ \mathrm{CoCl}_{3} .6 \mathrm{H}_{2} \mathrm{O} & 0.35 \mathrm{~g} / \mathrm{L}\end{array}$

Adjust $\mathrm{pH}$ to 7.0 with $10 \% \mathrm{HCl}$.

Autoclave at $121^{\circ} \mathrm{C}$, under $1.06-1.2 \mathrm{~kg} / \mathrm{cm} 2$ pressure for 30 minutes, and cool the mixtures. 
WC Media (Guillard \& Lorenzen, 1972) based on the Ontario Ministry of the Environment, this was used for the culturing and growth of Chlorella vulgaris and Cyclotella pseudostelligera.

\begin{tabular}{|c|c|}
\hline Component & Quantity \\
\hline Distilled water & $1000 \mathrm{~mL}$ \\
\hline \multicolumn{2}{|l|}{ Major nutrients } \\
\hline $\mathrm{Ca} \mathrm{Cl}_{2} .2 \mathrm{H}_{2} \mathrm{O}$ & $36.76 \mathrm{mg} / \mathrm{L}$ \\
\hline $\mathrm{MgSO}_{4} .7 \mathrm{H}_{2} \mathrm{O}$ & $36.97 \mathrm{mg} / \mathrm{L}$ \\
\hline $\mathrm{NaHCO}_{3}$ & $12.60 \mathrm{mg} / \mathrm{L}$ \\
\hline $\mathrm{K}_{2} \mathrm{HPO}_{4}$ & $8.71 \mathrm{mg} / \mathrm{L}$ \\
\hline $\mathrm{NaNO}_{3}$ & $85.01 \mathrm{mg} / \mathrm{L}$ \\
\hline $\mathrm{Na}_{2} \mathrm{SiO}_{3} .9 \mathrm{H}_{2} \mathrm{O}$ & $28.42 \mathrm{mg} / \mathrm{L}$ \\
\hline \multicolumn{2}{|l|}{ Traces } \\
\hline Na2.EDTA & $4.36 \mathrm{mg} / \mathrm{L}$ \\
\hline $\mathrm{FeCl}_{3} .6 \mathrm{H}_{2} \mathrm{O}$ & $3.15 \mathrm{mg} / \mathrm{L}$ \\
\hline $\mathrm{CuSO}_{4} .5 \mathrm{H}_{2} \mathrm{O}$ & $0.01 \mathrm{mg} / \mathrm{L}$ \\
\hline $\mathrm{ZnSO}_{4} .7 \mathrm{H}_{2} \mathrm{O}$ & $0.022 \mathrm{mg} / \mathrm{L}$ \\
\hline $\mathrm{CoCl}_{2} .6 \mathrm{H}_{2} \mathrm{O}$ & $0.01 \mathrm{mg} / \mathrm{L}$ \\
\hline $\mathrm{MnCl}_{2} .4 \mathrm{H}_{2} \mathrm{O}$ & $0.18 \mathrm{mg} / \mathrm{L}$ \\
\hline $\mathrm{Na}_{2} \mathrm{MoO}_{4} \cdot 2 \mathrm{H}_{2} \mathrm{O}$ & $0.006 \mathrm{mg} / \mathrm{L}$ \\
\hline $\mathrm{H}_{3} \mathrm{BO}_{3}$ & $1.0 \mathrm{mg} / \mathrm{L}$ \\
\hline \multicolumn{2}{|l|}{$\begin{array}{l}\text { Vitamins (if considered necessary) } \\
\text { *Absence of vitamins doesn't seem to affect } \\
\text { diatoms. }\end{array}$} \\
\hline Thiamin.HCl & $0.1 \mathrm{mg} / \mathrm{L}$ \\
\hline Biotin & $0.5 \mu \mathrm{g} / \mathrm{L}$ \\
\hline $\mathrm{B}_{12}$ & $0.5 \mu \mathrm{g} / \mathrm{L}$ \\
\hline
\end{tabular}




\section{Appendix II}

\section{Raw Growth and Photosynthetic Data}

Cyclotella pseudostelligera raw growth data:

\section{Graph of Net Production:}

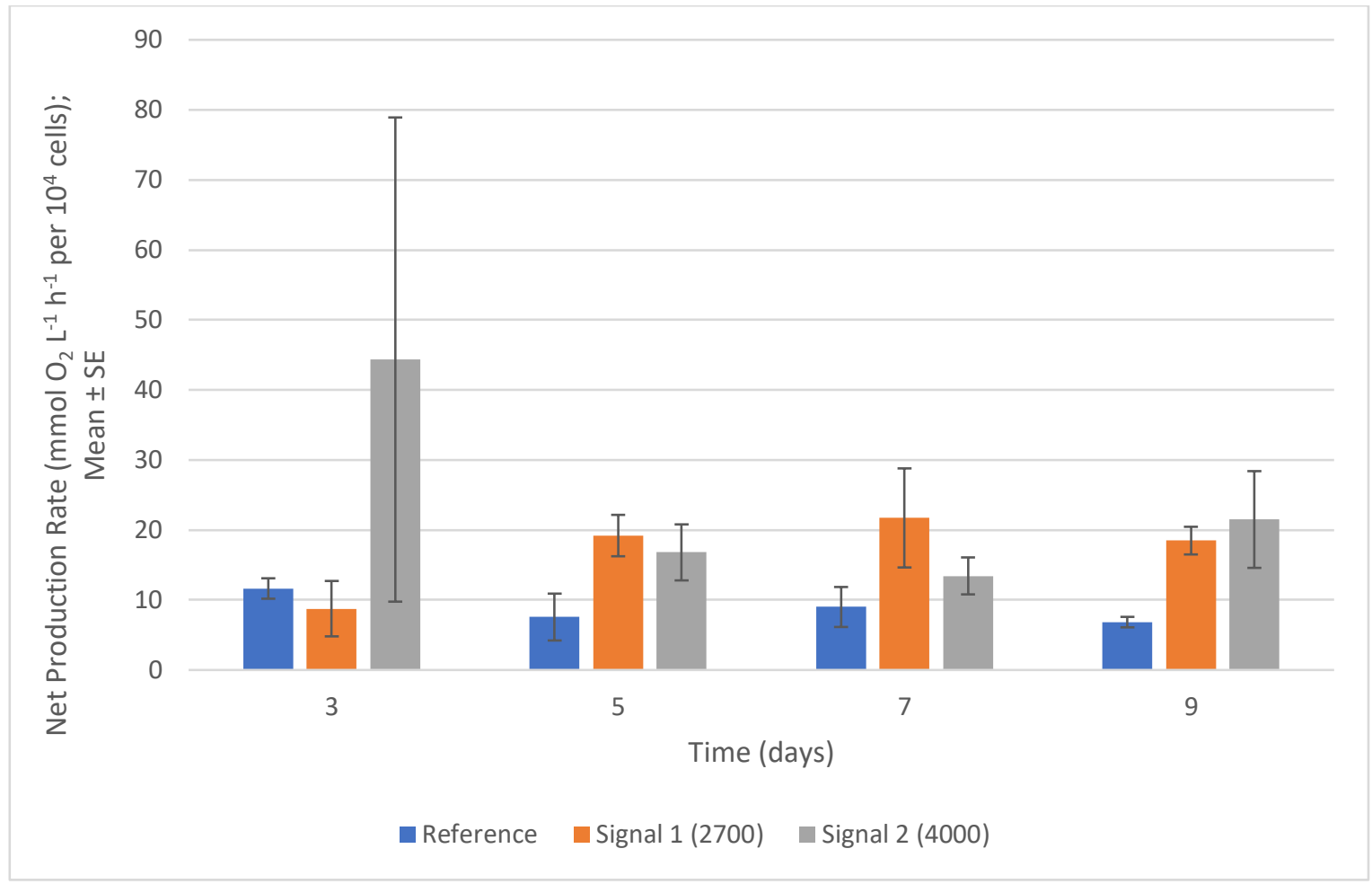

Fig. 3.4 C. pseudostelligera mean \pm standard error net production rates over time across different electromagnetic field conditions 


\section{Graph of Gross Production:}

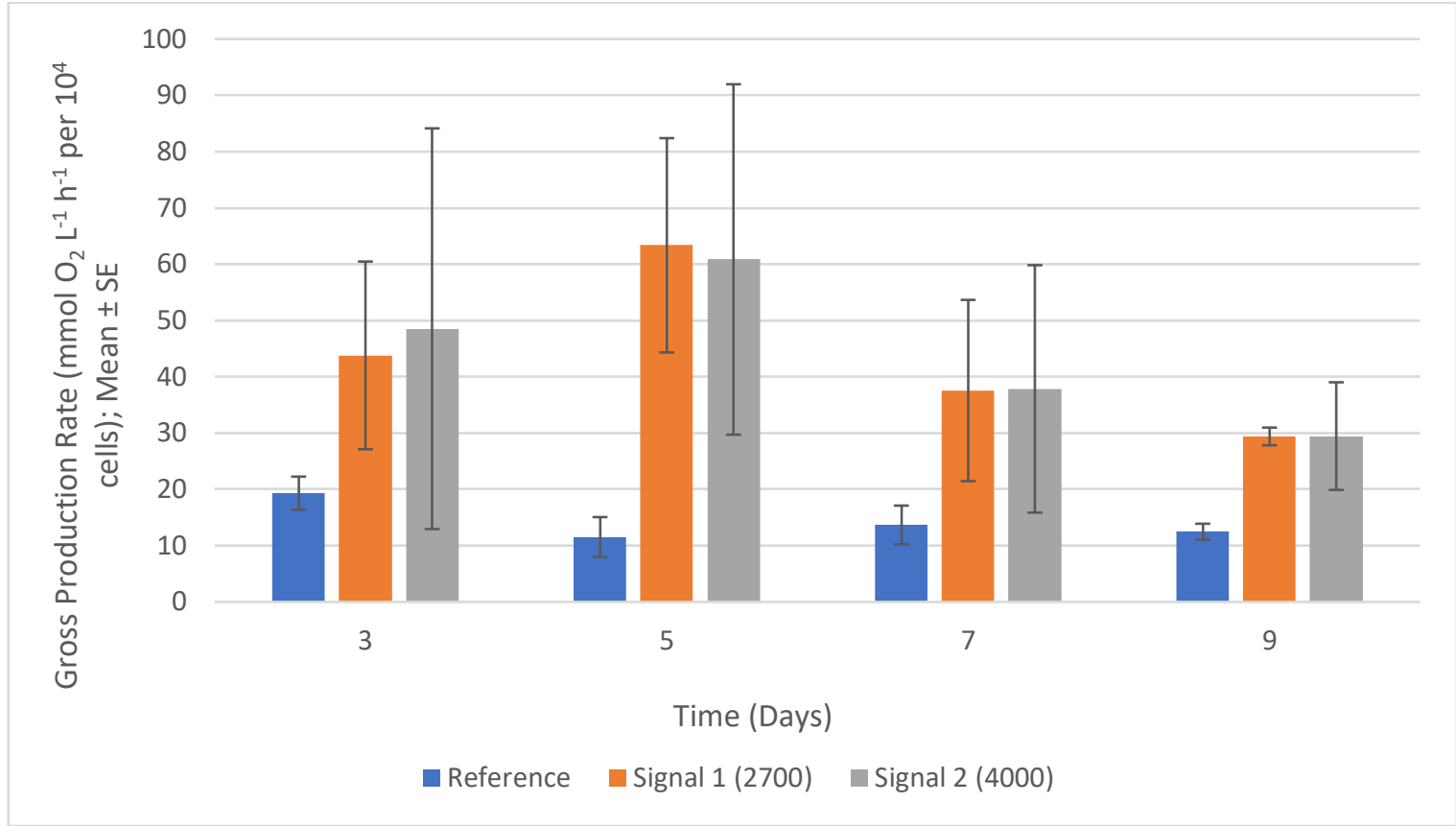

Fig. 3.5 C. pseudostelligera mean \pm standard error gross production rates over time across different electromagnetic field conditions

Raw and calculated counts from each day:

\begin{tabular}{|c|c|c|c|c|c|c|c|c|c|}
\hline & Replicate 1 & & & Replicate 2 & & & Replicate 3 & & \\
\hline Day & C & T1 & $\mathrm{T} 2$ & C & T1 & $\mathrm{T} 2$ & C & T1 & $\mathrm{T} 2$ \\
\hline 1 & 49 & 34 & 19 & 38 & 44 & 52 & 30 & 42 & 47 \\
\hline 2 & 81 & 69 & 104 & 91 & 116 & 99 & 92 & 73 & 86 \\
\hline 3 & 279 & 190 & 304 & 389 & 283 & 291 & 338 & 140 & 141 \\
\hline 4 & 361 & 243 & 392 & 296 & 250 & 462 & 398 & 165 & 189 \\
\hline 5 & 321 & 199 & 322 & 401 & 213 & 367 & 527 & 148 & 159 \\
\hline 6 & 330 & 386 & 295 & 477 & 150 & 520 & 603 & 237 & 225 \\
\hline 7 & 325 & 346 & 324 & 389 & 164 & 389 & 566 & 175 & 266 \\
\hline 9 & 358 & 289 & 181 & 404 & 256 & 385 & 765 & 244 & 152 \\
\hline & & & & & & & & & \\
\hline & & & & & & & & & \\
\hline & & & & & & & & & \\
\hline & & & & & & & & & \\
\hline & & & & & & & & & \\
\hline Total Counts & C & T1 & $\mathrm{T} 2$ & C & T1 & $\mathrm{T} 2$ & C & T1 & $\mathrm{T} 2$ \\
\hline 1 & 435556 & 302222 & 168889 & 337778 & 391111 & 462222 & 266667 & 373333 & 417778 \\
\hline 2 & 720000 & 613333 & 924444 & 808889 & 1031111 & 880000 & 817778 & 648889 & 764444 \\
\hline 3 & 2480000 & 1688889 & 2702222 & 3457778 & 2515556 & 2586667 & 3004444 & 1244444 & 1253333 \\
\hline 4 & 3208889 & 2160000 & 3484444 & 2631111 & 2222222 & 4106667 & 3537778 & 1466667 & 1680000 \\
\hline 5 & 2853333 & 1768889 & 2862222 & 3564444 & 1893333 & 3262222 & 4684444 & 1315556 & 1413333 \\
\hline 6 & 2933333 & 3431111 & 2622222 & 4240000 & 1333333 & 4622222 & 5360000 & 2106667 & 2000000 \\
\hline 7 & 2888889 & 3075556 & 2880000 & 3457778 & 1457778 & 3457778 & 5031111 & 1555556 & 2364444 \\
\hline 9 & 3182222 & 2568889 & 1608889 & 3591111 & 2275556 & 3422222 & 6800000 & 2168889 & 1351111 \\
\hline
\end{tabular}


Calculated growth rates and carrying capacities:

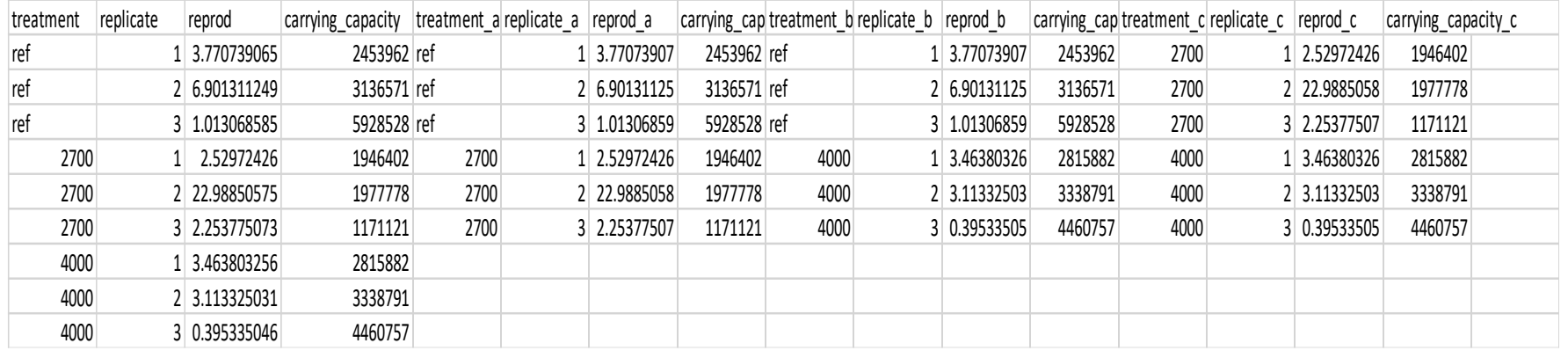

\section{Cyclotella pseudostelligera raw photosynthetic data:}

\section{Calculated photosynthetic values from raw data:}

\begin{tabular}{|c|c|c|c|c|c|c|c|c|c|c|c|c|c|c|}
\hline Day & treatment & replicate & respiration & net_prod & gross_prod & resp_norm & net_norm & gross_norm & normalized time resp & net prod & gross prod & log resp & log net prod & log gross prod \\
\hline & ref & 1 & 0.2972 & 0.8069 & 1.1041 & 0.00000012 & 0.00000033 & 0.00000045 & 4.32 & 11.88 & 16.20 & 0.63548375 & 1.07481644 & 1.209515015 \\
\hline & 1 ref & 2 & 1.5483 & 0.8731 & 2.4214 & 0.00000045 & 0.00000025 & 0.0000007 & 16.20 & 9.00 & 25.20 & 1.20951501 & 0.95424251 & 1.401400541 \\
\hline & 1 ref & 3 & 0.2232 & 1164 & 1.3872 & 0.00000007 & 0.00000039 & 0.00000046 & 2.52 & 14.04 & 16.56 & 0.40140054 & 1.14736711 & 1.219060332 \\
\hline & ref & 1 & 0.4529 & 0.9765 & 1.4294 & 0.00000016 & 0.00000034 & 0.0000005 & 5.76 & 12.24 & 18.00 & 0.76042248 & 1.08778142 & 1.255272505 \\
\hline & 2 ref & 2 & 0.1688 & 0.9181 & 1.0869 & 0.00000005 & 0.00000026 & 0.0000003 & 1.80 & 9.36 & 10.80 & 0.25527251 & 0.97127585 & 1.033423755 \\
\hline & ref & 3 & 0.6061 & 0.1435 & 0.7496 & 0.00000013 & 0.00000003 & 0.00000016 & 4.68 & 1.08 & 5.76 & 0.67024585 & 0.03342376 & 0.760422483 \\
\hline & 3 ref & 1 & 0.49 & 1.0625 & 1.5525 & 0.00000017 & 0.00000037 & 0.00000054 & 6.12 & 13.32 & 19.44 & 0.78675142 & 1.12450422 & 1.288696261 \\
\hline & 3 ref & 2 & 0.3896 & 0.9528 & 1.3423 & 0.00000011 & 0.00000028 & 0.00000039 & 3.96 & 10.08 & 14.04 & 0.59769519 & 1.00346053 & 1.147367108 \\
\hline & 3 ref & 3 & 0.5407 & 0.5063 & 1.047 & 0.0000001 & 1. 0.0000001 & 0.00000021 & 3.60 & 3.60 & 7.56 & 0.5563025 & 0.5563025 & 0.878521796 \\
\hline & + ref & 1 & 0.6718 & 0.5132 & 1.185 & 0.00000021 & 0.00000016 & 0.00000037 & 7.56 & 5.76 & 13.32 & 0.8785218 & 0.76042248 & 1.124504225 \\
\hline & + ref & 2 & 0.6009 & 0.8223 & 1.4232 & 0.00000017 & 0.00000023 & 0.0000004 & 6.12 & 8.28 & 14.40 & 0.78675142 & 0.91803034 & 1.158362492 \\
\hline & 4 ref & 3 & 0.5796 & 1.2339 & 1.8135 & 0.00000018 & 0.00000018 & 0.00000027 & 6.48 & 6.48 & 9.72 & 0.81157501 & 0.81157501 & 0.987666265 \\
\hline 1 & 2700 & 1 & 0.4102 & 0.7485 & 1.1587 & 0.00000024 & 0.00000044 & 0.00000069 & 8.64 & 15.84 & 24.84 & 0.93651374 & 1.19975518 & 1.395151592 \\
\hline 1 & 2700 & 2 & 1.4797 & 0.576 & 2.0557 & 0.00000059 & 0.00000023 & 0.00000082 & 21.24 & 8.28 & 29.52 & 1.32715451 & 0.91803034 & 1.470116353 \\
\hline 1 & 2700 & 3 & 2.5875 & 0.0729 & 2.6604 & 0.00000208 & 0.00000006 & 0.00000214 & 74.88 & 2.16 & 77.04 & 1.87436584 & 0.33445375 & 1.886716274 \\
\hline 2 & 2700 & 1 & 0.3301 & 1.062 & 1.3921 & 0.00000019 & 0.0000006 & 0.00000079 & 6.84 & 21.60 & 28.44 & 0.8350561 & 1.33445375 & 1.453929592 \\
\hline 2 & 2700 & 2 & 4.2519 & 0.6928 & 4.9447 & 0.00000225 & 0.00000037 & 0.00000261 & 81.00 & 13.32 & 93.96 & 1.90848502 & 1.12450422 & 1.972943008 \\
\hline 2 & 2700 & 3 & 1.6446 & 0.228 & 2.4674 & 0.00000125 & 0.00000063 & 0.00000188 & 45.00 & 22.68 & 67.68 & 1.65321251 & 1.35564305 & 1.83046035 \\
\hline 3 & 2700 & 1 & 0.4697 & 0.68 & 1.1497 & 0.00000015 & 0.00000022 & 0.00000037 & 5.40 & 7.92 & 13.32 & 0.73239376 & 0.89872518 & 1.124504225 \\
\hline 3 & 2700 & 2 & 1.4769 & 1.2711 & 2.748 & 0.00000101 & 0.00000087 & 0.00000189 & 36.36 & 31.32 & 68.04 & 1.56062387 & 1.49582175 & 1.832764305 \\
\hline 3 & 2700 & 3 & 0.2311 & 1.1166 & 1.3477 & 0.00000015 & 0.00000072 & 0.00000087 & 5.40 & 25.92 & 31.32 & 0.73239376 & 1.413635 & 1.495821753 \\
\hline 4 & 2700 & 1 & 1.1755 & 1.0708 & 2.2463 & 0.00000046 & 0.00000042 & 0.00000087 & 16.56 & 15.12 & 31.32 & 1.21906033 & 1.17955179 & 1.495821753 \\
\hline 4 & 2700 & 2 & 0.4887 & 1.1643 & 1.653 & 0.00000021 & 0.00000051 & 0.00000073 & 7.56 & 18.36 & 26.28 & 0.8785218 & 1.26387268 & 1.419625361 \\
\hline 4 & 2700 & 3 & 0.5111 & 1.3289 & 1.84 & 0.00000024 & 0.00000061 & 0.00000085 & 8.64 & 21.96 & 30.60 & 0.93651374 & 1.34163234 & 1.485721426 \\
\hline 1 & 4000 & 1 & 0.3428 & 0.9285 & 1.2713 & 0.00000013 & 0.00000034 & 0.00000047 & 4.57 & 12.37 & 16.94 & 0.65962378 & 1.09236324 & 1.228829821 \\
\hline 1 & 4000 & 2 & 0.1347 & 0.519 & 0.6537 & 0.00000005 & 0.00000020 & 0.00000025 & 1.87 & 7.22 & 9.10 & 0.27292928 & 0.85872868 & 0.958940395 \\
\hline 1 & 4000 & 3 & 0.2148 & 3.9487 & 4.1635 & 0.00000017 & 0.00000315 & 0.00000332 & 6.17 & 113.42 & 119.59 & 0.79027024 & 2.05469026 & 2.077694285 \\
\hline 2 & 4000 & 1 & 2.8804 & 1.2643 & 4.1447 & 0.00000101 & 0.00000044 & 0.00000145 & 36.23 & 15.90 & 52.13 & 1.55905155 & 1.20144956 & 1.717092057 \\
\hline 2 & 4000 & 2 & 0.1329 & 0.9386 & 1.0715 & 0.00000004 & 0.00000029 & 0.00000033 & 1.47 & 10.36 & 11.82 & 0.16631393 & 1.01526953 & 1.072781023 \\
\hline 2 & 4000 & 3 & 3.7083 & 0.9473 & 4.6556 & 0.00000262 & 0.00000067 & 0.00000329 & 94.46 & 24.13 & 118.59 & 1.97523323 & 1.3825458 & 2.074034006 \\
\hline 3 & 4000 & 1 & 0.3788 & 1.3555 & 1.7343 & 0.00000013 & 0.00000047 & 0.00000060 & 4.74 & 16.94 & 21.68 & 0.67532072 & 1.22900979 & 1.336034598 \\
\hline 3 & 4000 & 2 & 0.218 & 0.7943 & 1.0123 & 0.00000006 & 0.00000023 & 0.00000029 & 2.27 & 8.27 & 10.54 & 0.3559621 & 0.91748996 & 1.022814239 \\
\hline 3 & 4000 & 3 & 4.3501 & 0.9925 & 5.3426 & 0.00000184 & 0.00000042 & 0.00000226 & 66.23 & 15.11 & 81.34 & 1.82107312 & 1.17930355 & 1.910326379 \\
\hline 4 & 4000 & 1 & 0.3362 & 0.8084 & 1.1446 & 0.00000021 & 0.00000050 & 0.00000071 & 7.52 & 18.09 & 25.61 & 0.87637397 & 1.25740313 & 1.408430402 \\
\hline 4 & 4000 & 2 & 0.3381 & 1027 & 1.4408 & .00000010 & 0.00000032 & 0.00000042 & 3.56 & 11.60 & 15.16 & 0.551039 & 1.0644523 & 180 \\
\hline 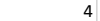 & 7 & 3 & 0.482 & 13057 & & & & & & 34.79 & 4761 & & & \\
\hline
\end{tabular}




\section{Calculated averages and standard errors:}

\begin{tabular}{|c|c|c|c|c|c|c|}
\hline & \multicolumn{3}{|c|}{ Respiration } \\
\hline ref & & 2700 & 4000 & & & \\
\hline & & & & & & \\
\hline 4.32 & & 8.64 & 4.57 & & & \\
\hline 16.2 & & 21.24 & 1.87 & & & \\
\hline 2.52 & & 74.88 & 6.17 & & & \\
\hline 5.76 & & 6.84 & 36.23 & & & \\
\hline 1.8 & & 81 & 1.47 & & & \\
\hline 4.68 & & 45 & 94.46 & & & \\
\hline 6.12 & & 5.4 & 4.74 & & & \\
\hline 3.96 & & 36.36 & 2.27 & & & \\
\hline 3.6 & & 5.4 & 66.23 & & & \\
\hline 7.56 & & 16.56 & 7.52 & & & \\
\hline 6.12 & & 7.56 & 3.56 & & & \\
\hline 6.48 & & 8.64 & 12.82 & & & \\
\hline & & & & & & \\
\hline & & & & & & \\
\hline std dev: & & & & & & \\
\hline 7.43322272 & 35.1751503 & 2.17332311 & & & & \\
\hline 2.04704665 & 37.0852423 & 46.9860451 & & & & \\
\hline 1.362938 & 17.8747643 & 36.2353478 & & & & \\
\hline 0.74939976 & 4.91414286 & 4.64613101 & & & & \\
\hline & & & & & & \\
\hline & & & & Time (days) Reference & Signal $1(2700)$ & Signal 2 (4000) \\
\hline $\begin{array}{l}\text { std error: } \\
4.29157314\end{array}$ & 20.3083825 & 1.25476868 & & 37.68 & 34.92 & 4.203333333 \\
\hline 1.18186294 & 21.4111747 & 27.1274058 & & 4.08 & 44.28 & 44.05333333 \\
\hline 0.78689262 & 10.32 & 20.9204878 & & 4.56 & 15.72 & 24.41333333 \\
\hline 0.43266615 & 2.8371817 & 2.68244499 & & 6.72 & $10.92^{\prime}$ & 7.966666667 \\
\hline
\end{tabular}


Net Production

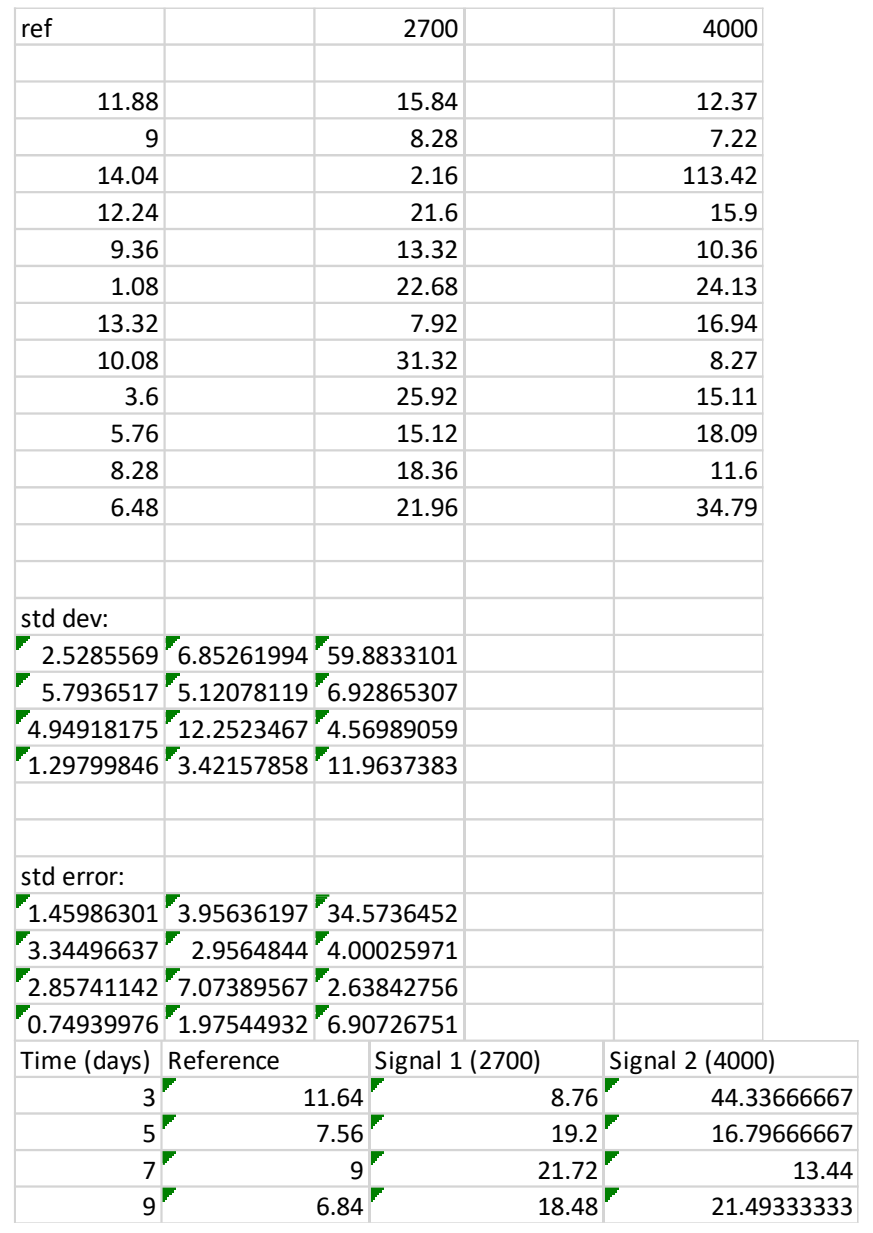


Gross Production

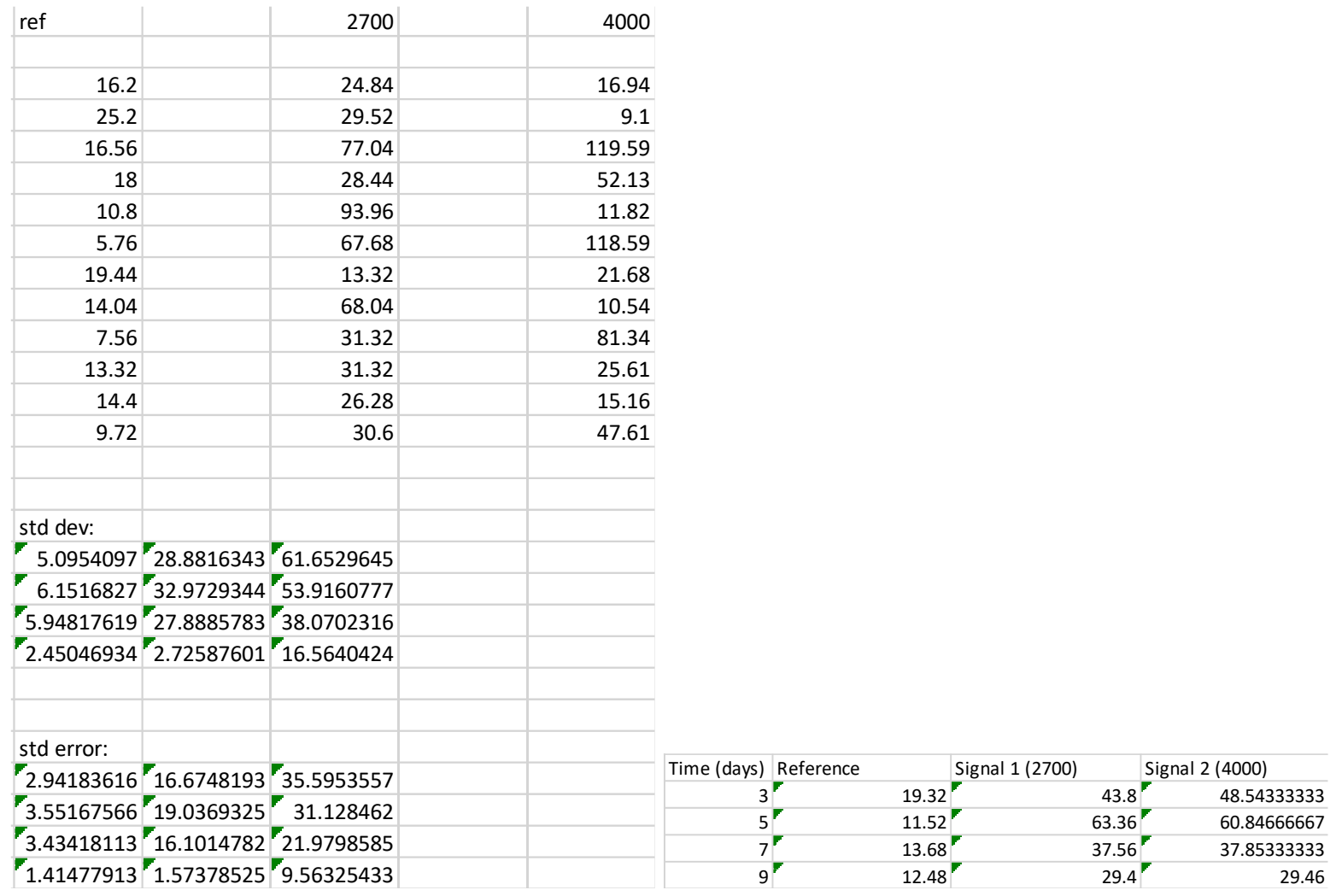

Chlorella vulgaris raw growth data:

\section{Raw and calculated counts from each day:}

\begin{tabular}{|c|c|c|c|c|c|c|c|c|c|}
\hline & Replicate 1 & & & Replicate 2 & & & Replicate 3 & & \\
\hline Day & C & T1 & $\mathrm{T} 2$ & C & T1 & $\mathrm{T} 2$ & C & T1 & T2 \\
\hline 1 & 7 & 5 & 4 & 4 & 5 & 5 & 9 & 7 & 8 \\
\hline 2 & 6 & 7 & 11 & 5 & 9 & 6 & 7 & 9 & 11 \\
\hline 3 & 13 & 8 & 10 & 15 & 13 & 7 & 16 & 5 & 12 \\
\hline 4 & 13 & 25 & 15 & 52 & 18 & 10 & 24 & 7 & 12 \\
\hline 5 & 44 & 48 & 46 & 68 & 70 & 81 & 98 & 65 & 87 \\
\hline 6 & 89 & 119 & 128 & 97 & 109 & 117 & 166 & 139 & 118 \\
\hline 7 & 111 & 173 & 179 & 92 & 118 & 203 & 155 & 222 & 166 \\
\hline 8 & 119 & 215 & 256 & 76 & 149 & 164 & 182 & 252 & 205 \\
\hline 9 & 110 & 242 & 444 & 98 & 206 & 150 & 267 & 196 & 167 \\
\hline & & & & & & & & & \\
\hline & & & & & & & & & \\
\hline & & & & & & & & & \\
\hline & & & & & & & & & \\
\hline Total Counts & C & T1 & $\mathrm{T} 2$ & C & T1 & $\mathrm{T} 2$ & C & T1 & T2 \\
\hline 1 & 62222 & 44444 & 35556 & 35556 & 44444 & 44444 & 80000 & 62222 & 71111 \\
\hline 2 & 53333 & 62222 & 97778 & 44444 & 80000 & 53333 & 62222 & 80000 & 97778 \\
\hline 3 & 115556 & 71111 & 88889 & 133333 & 115556 & 62222 & 142222 & 44444 & 106667 \\
\hline 4 & 115556 & 222222 & 133333 & 462222 & 160000 & 88889 & 213333 & 62222 & 106667 \\
\hline 5 & 391111 & 426667 & 408889 & 604444 & 622222 & 720000 & 871111 & 577778 & 773333 \\
\hline 6 & 791111 & 1057778 & 1137778 & 862222 & 968889 & 1040000 & 1475556 & 1235556 & 1048889 \\
\hline 7 & 986667 & 1537778 & 1591111 & 817778 & 1048889 & 1804444 & 1377778 & 1973333 & 1475556 \\
\hline 8 & 1057778 & 1911111 & 2275556 & 675556 & 1324444 & 1457778 & 1617778 & 2240000 & 1822222 \\
\hline 9 & 604444 & 977778 & 3946667 & 604444 & 1831111 & 1333333 & 711111 & 1742222 & 1457778 \\
\hline
\end{tabular}


Calculated growth rates and carrying capacities:

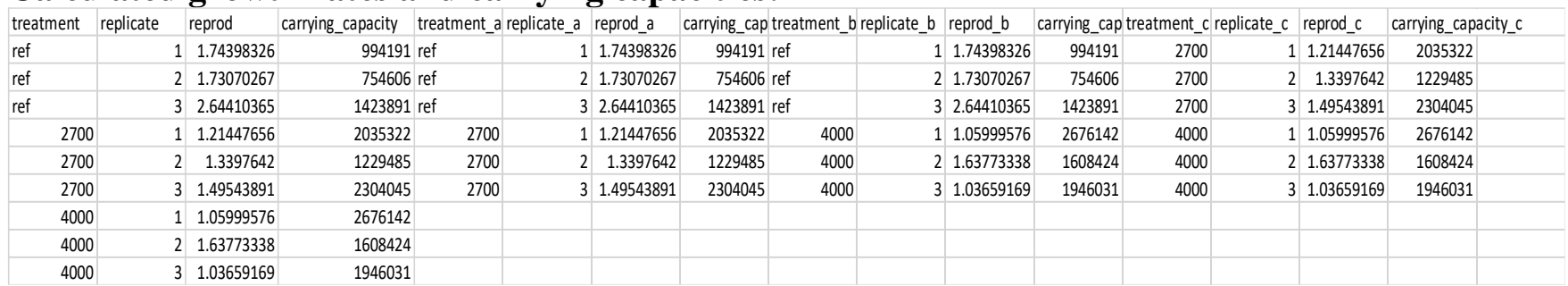

Chlorella vulgaris raw photosynthetic data:

\section{Graph of Net Production:}

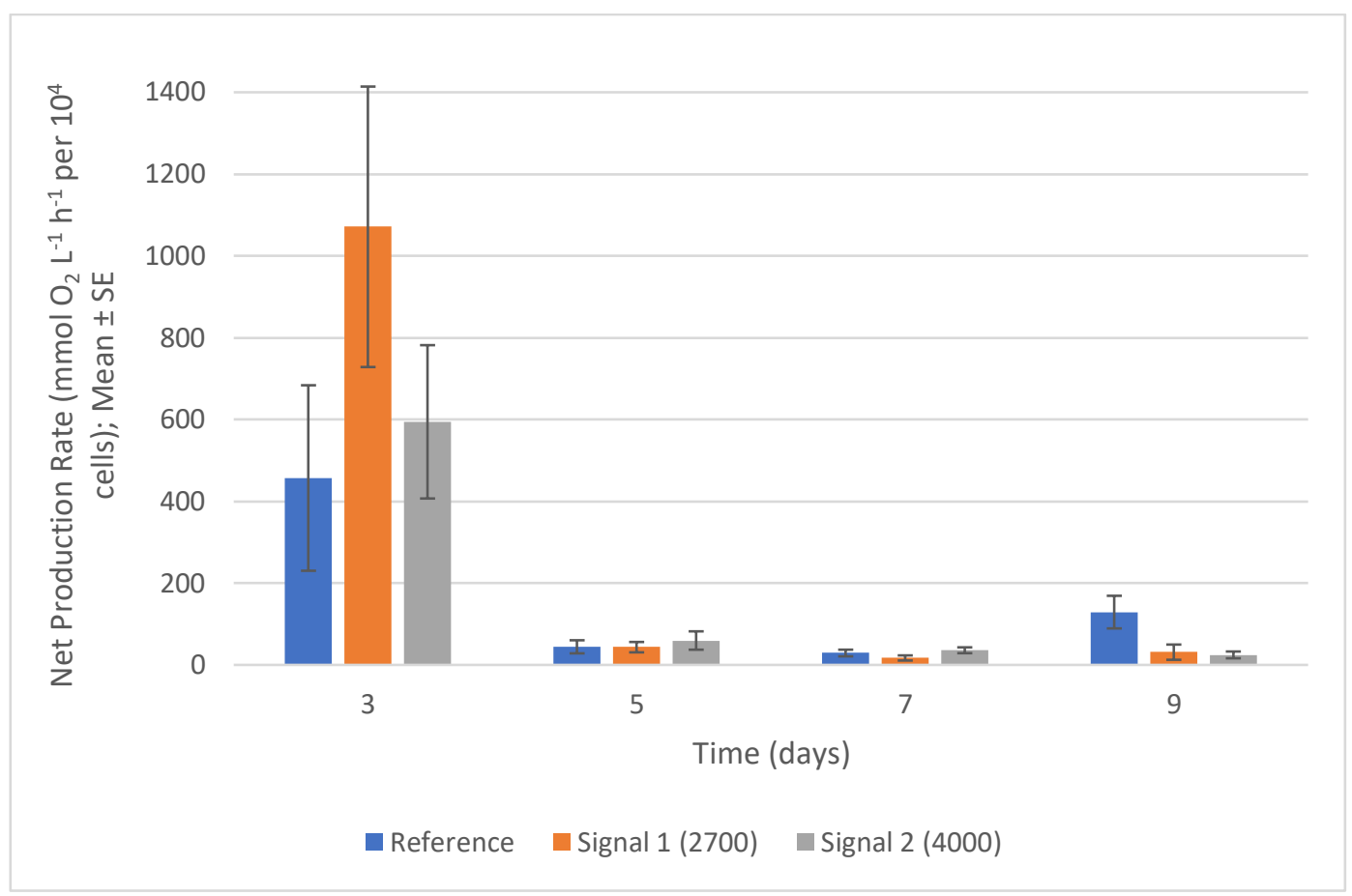

Fig. 3.6 C. vulgaris mean \pm standard error net production rates over time across different electromagnetic field conditions 


\section{Graph of Gross Production:}

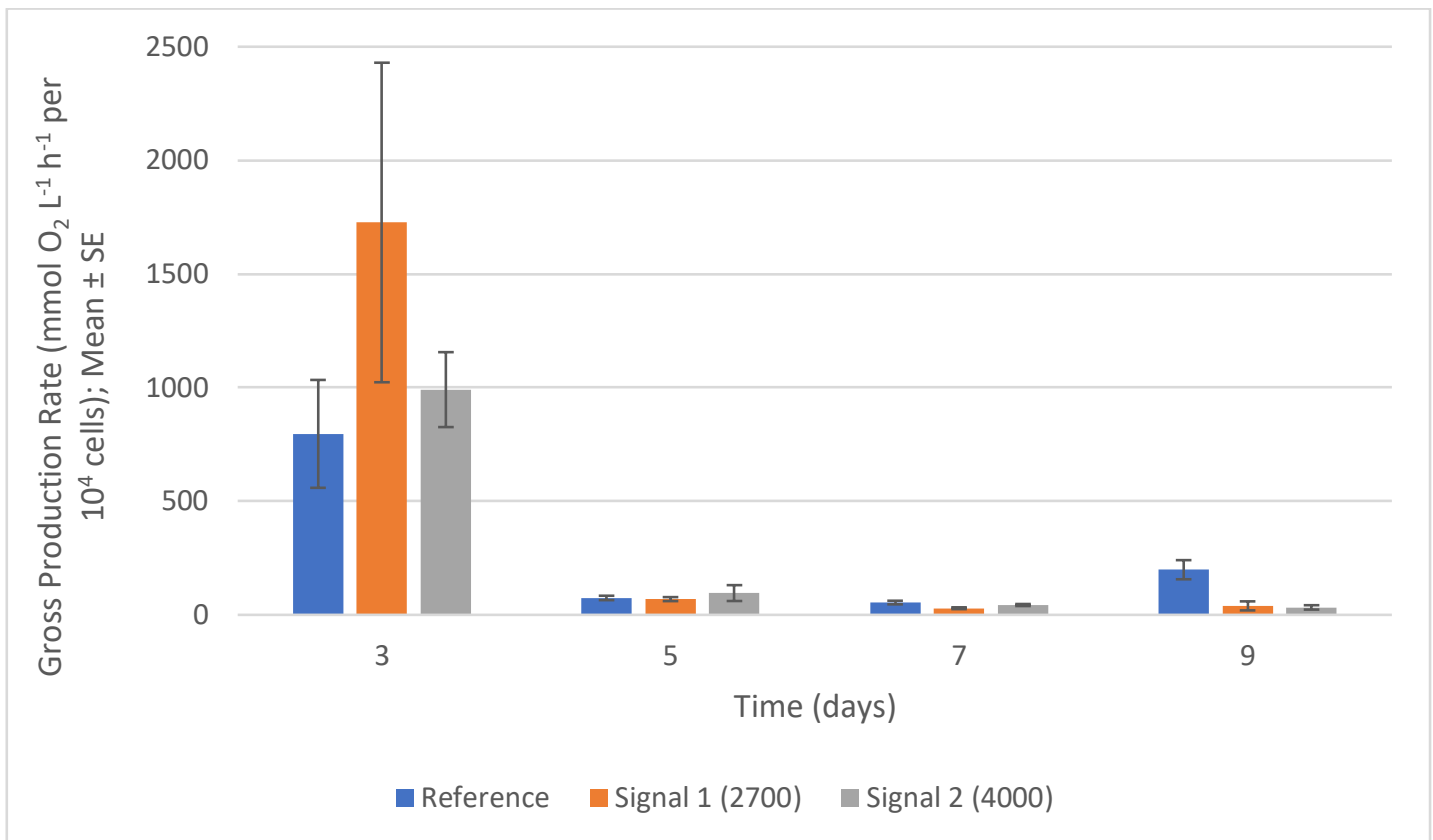

Fig. 3.7 C. vulgaris mean \pm standard error gross production rates over time across different electromagnetic field conditions

\section{Calculated photosynthetic values from raw data:}

\begin{tabular}{|c|c|c|c|c|c|c|c|c|c|c|c|c|c|c|}
\hline Day & treatment & replicate & respiration & net_prod & gross_prod & resp_norm & net_norm & gross_norm & normalized time resp & net prod & gross prod & log resp & log net prod & log gross prod \\
\hline & ref & 1 & 1.0456 & 2.9087 & 3.9543 & 0.00000905 & 0.00002517 & 0.00003422 & 325.74 & 906.17 & 1231.91 & 2.51287573 & 2.95720815 & 3.090579968 \\
\hline & ref & 2 & 0.4757 & 1.0607 & 1.5364 & 0.00000357 & 0.00000796 & 0.00001152 & 128.44 & 286.39 & 414.83 & 2.10869813 & 2.45695742 & 2.617868063 \\
\hline & ref & 3 & 2.2285 & 0.705 & 2.9335 & 0.00001567 & 0.00000496 & 0.00002063 & 564.09 & 178.45 & 742.54 & 2.75134932 & 2.25152492 & 2.870721725 \\
\hline & ref & 1 & 0.6375 & 0.3251 & 0.9626 & 0.00000163 & 0.00000083 & 0.00000246 & 58.68 & 29.92 & 88.60 & 1.76848211 & 1.47601953 & 1.947447643 \\
\hline & ref & 2 & 0.0416 & 1.2801 & 1.3217 & 0.00000007 & 0.00000212 & 0.00000219 & 2.48 & 76.24 & 78.72 & 0.39403989 & 1.8821895 & 1.896079789 \\
\hline & ref & 3 & 0.7087 & 0.6464 & 1.3551 & 0.00000081 & 0.00000074 & 0.00000156 & 29.29 & 26.71 & 56.00 & 1.46669155 & 1.4267304 & 1.748200435 \\
\hline & ref & 1 & 0.5885 & 0.55887 & 1.1772 & 0.00000060 & 0.00000060 & 0.00000119 & 21.47 & 21.48 & 42.95 & 1.33187873 & 1.33202579 & 1.632982987 \\
\hline & ref & 2 & 0.5478 & 1.03 & 1.5778 & 0.00000067 & 0.00000126 & 0.00000193 & 24.12 & 45.34 & 69.46 & 1.38228914 & 1.65650412 & 1.841718022 \\
\hline & ref & 3 & 1.1291 & 0.7895 & 1.9186 & 0.00000082 & 0.00000057 & 0.00000139 & 29.50 & 20.63 & 50.13 & 1.4698557 & 1.31447531 & 1.700107061 \\
\hline & ref & 1 & 1.7421 & 0.957 & 2.6991 & 0.00000288 & 0.00000158 & 0.00000447 & 103.76 & 57.00 & 160.76 & 2.01601908 & 1.75585748 & 2.206165787 \\
\hline & ref & 2 & 1.4791 & 3.2676 & 4.7461 & 0.00000245 & 0.00000541 & 0.00000785 & 88.09 & 194.61 & 282.69 & 1.94494357 & 2.28917533 & 2.451310999 \\
\hline & ref & 3 & 0.3302 & 2.6824 & 3.0126 & 0.00000046 & 0.00000377 & 0.00000424 & 16.72 & 135.80 & 152.51 & 1.22314234 & 2.13288915 & 2.183306636 \\
\hline 1 & 2700 & 1 & 0.4485 & 1.5146 & 1.9631 & 0.00000631 & 0.00002130 & 0.00002761 & 227.16 & 766.80 & 993.96 & 2.35633186 & 2.8846821 & 2.997368907 \\
\hline 1 & 2700 & 2 & 1.1623 & 2.2186 & 3.3809 & 0.00001006 & 0.00001920 & 0.00002926 & 362.16 & 691.20 & 1053.36 & 2.55890048 & 2.83960373 & 3.022576823 \\
\hline 1 & 2700 & 3 & 1.7 & 2.1669 & 3.8669 & 0.00003825 & 0.00004876 & 0.00008701 & 1377.00 & 1755.36 & 3132.36 & 3.13893394 & 3.2443662 & 3.495871669 \\
\hline 2 & 2700 & 1 & 0.2122 & 0.8142 & 1.0264 & 0.00000050 & 0.00000191 & 0.00000241 & 18.00 & 68.76 & 86.76 & 1.25527251 & 1.83733587 & 1.938319543 \\
\hline 2 & 2700 & 2 & 0.485 & 0.5263 & 1.0113 & 0.00000078 & 0.00000085 & 0.00000163 & 28.08 & 30.60 & 58.68 & 1.4483971 & 1.48572143 & 1.768490105 \\
\hline 2 & 2700 & 3 & 0.5025 & 0.4967 & 0.9992 & 0.00000087 & 0.00000086 & 0.00000173 & 31.32 & 30.96 & 62.28 & 1.49582175 & 1.49080095 & 1.794348604 \\
\hline 3 & 2700 & 1 & 1.1487 & 0.234 & 1.3827 & 0.00000075 & 0.00000015 & 0.00000090 & 27.00 & 5.40 & 32.40 & 1.43136376 & 0.73239376 & 1.51054501 \\
\hline 3 & 2700 & 2 & 0.2002 & 0.7892 & 0.9894 & 0.00000019 & 0.00000075 & 0.00000094 & 6.84 & 27.00 & 33.84 & 0.8350561 & 1.43136376 & 1.529430354 \\
\hline 3 & 2700 & 3 & 0.1409 & 1.0261 & 1.167 & 0.00000007 & 0.00000052 & 0.00000059 & 2.52 & 18.72 & 21.24 & 0.40140054 & 1.27230584 & 1.327154512 \\
\hline 4 & 2700 & 1 & 0.3436 & 1.7858 & 2.1294 & 0.00000035 & 0.00000183 & 0.00000218 & 12.60 & 65.88 & 78.48 & 1.10037055 & 1.81875359 & 1.894758994 \\
\hline 4 & 2700 & 2 & 0.1019 & 1.2959 & 1.3978 & 0.00000006 & 0.00000071 & 0.00000076 & 2.16 & 25.56 & 27.36 & 0.33445375 & 1.40756085 & 1.437116093 \\
\hline 4 & 2700 & 3 & 0.5109 & 0.1088 & 0.6197 & 0.00000029 & 0.00000006 & 0.00000036 & 10.44 & 2.16 & 12.96 & 1.0187005 & 0.33445375 & 1.112605002 \\
\hline 1 & 4000 & 1 & 1.1448 & 0.7434 & 2.1914 & 0.00001288 & 0.00000836 & 0.00002465 & 463.64 & 301.08 & 887.52 & 2.66618464 & 2.47867706 & 2.9481758 \\
\hline 1 & 4000 & 2 & 0.641 & 1.6302 & 2.2712 & 0.00001030 & 0.00002620 & 0.00003650 & 370.86 & 943.19 & 1314.06 & 2.56921561 & 2.97459882 & 3.118614402 \\
\hline 1 & 4000 & 3 & 0.6911 & 1.596 & 2.2871 & 0.00000648 & 0.00001496 & 0.00002144 & 233.25 & 538.65 & 771.89 & 2.36781316 & 2.73130666 & 2.887557665 \\
\hline 2 & 4000 & 1 & 0.6353 & 1.1488 & 1.7841 & 0.00000155 & 0.00000281 & 0.00000436 & 55.93 & 101.14 & 157.08 & 1.74767526 & 2.00494081 & 2.196116579 \\
\hline 2 & 4000 & 2 & 0.2719 & 0.4808 & 0.7227 & 0.00000038 & 0.00000067 & 0.00000100 & 13.60 & 24.04 & 36.14 & 1.13337934 & 1.38093461 & 1.557928059 \\
\hline 2 & 4000 & 3 & 0.8666 & 1.1594 & 2.026 & 0.00000112 & 0.00000150 & 0.00000262 & 40.34 & 53.97 & 94.31 & 1.60575312 & 1.73216787 & 1.974575612 \\
\hline 3 & 4000 & 1 & 0.4208 & 1.5258 & 1.9466 & 0.00000026 & 0.00000096 & 0.00000122 & 9.52 & 34.52 & 44.04 & 0.97867727 & 1.53809982 & 1.643878077 \\
\hline 3 & 4000 & 2 & 0.5403 & 1.215 & 1.7553 & 0.00000030 & 0.00000067 & 0.00000097 & 10.78 & 24.24 & 35.02 & 1.03259346 & 1.38453563 & 1.544310437 \\
\hline 3 & 4000 & 3 & 0.0768 & 2.001 & 2.0778 & 0.00000005 & 0.00000136 & 0.00000141 & 1.87 & 48.82 & 50.69 & 0.27270822 & 1.68859422 & 1.70495142 \\
\hline 4 & 4000 & 1 & 0.731 & 1.0747 & 1.8057 & 0.00000019 & 0.00000027 & 0.00000046 & 6.67 & 9.80 & 16.47 & 0.82399038 & 0.99135971 & 1.21671733 \\
\hline 4 & 4000 & 2 & 0.4119 & 1.4237 & 1.8356 & 0.00000031 & 0.00000107 & 0.00000138 & 11.12 & 38.44 & 49.56 & 1.04615556 & 1.58478428 & 1.695141813 \\
\hline 4 & 4000 & 3 & 0.2859 & 1.027 & 1.3129 & 0.00000020 & 0.00000070 & 0.00000090 & 7.06 & 25.36 & 32.42 & 0.84882439 & 1.40418165 & 1.510842641 \\
\hline
\end{tabular}




\section{Calculated averages and standard errors:}

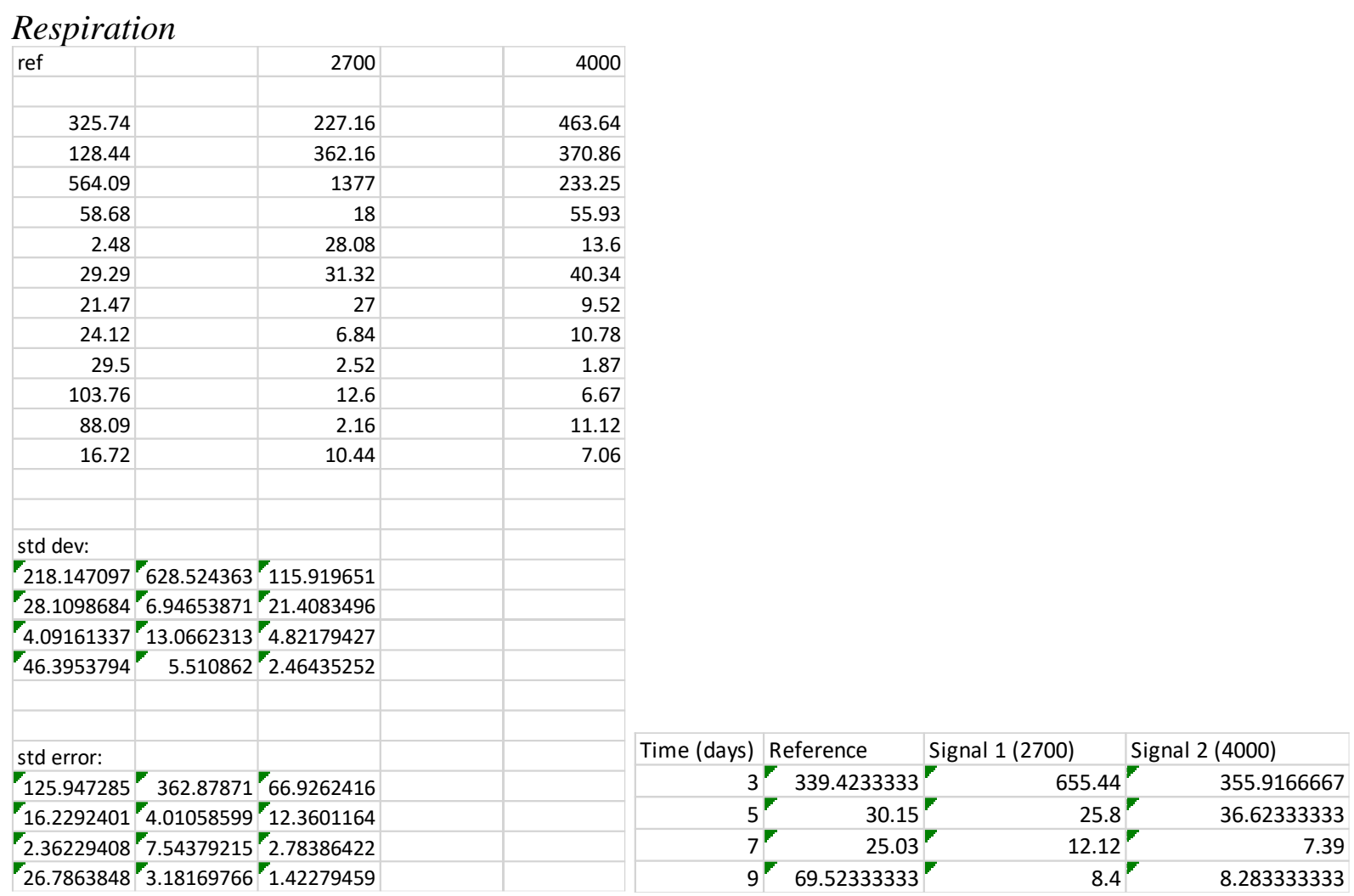

Net Production

\begin{tabular}{|c|c|c|c|c|c|c|c|}
\hline ref & & 2700 & 4000 & & & & \\
\hline & & & & & & & \\
\hline 906.17 & & 766.8 & 301.08 & & & & \\
\hline 286.39 & & 691.2 & 943.19 & & & & \\
\hline 178.45 & & 1755.36 & 538.65 & & & & \\
\hline 29.92 & & 68.76 & 101.14 & & & & \\
\hline 76.24 & & 30.6 & 24.04 & & & & \\
\hline 26.71 & & 30.96 & 53.97 & & & & \\
\hline 21.48 & & 5.4 & 34.52 & & & & \\
\hline 45.34 & & 27 & 24.24 & & & & \\
\hline 20.63 & & 18.72 & 48.82 & & & & \\
\hline 57 & & 65.88 & 9.8 & & & & \\
\hline 194.61 & & 25.56 & 38.44 & & & & \\
\hline 135.8 & & 2.16 & 25.36 & & & & \\
\hline & & & & & & & \\
\hline std dev: & & & & & & & \\
\hline 392.715905 & 593.77363 & 324.652986 & & & & & \\
\hline 27.7160224 & 21.928502 & 38.8699194 & & & & & \\
\hline 14.0273911 & 10.8975594 & 12.3446669 & & & & & \\
\hline 69.0465642 & 32.2322323 & 14.3378845 & & & & & \\
\hline & & & & & & & \\
\hline & & & & Time (days) & Reference & Signal 1 (2700) & jignal 2 (4000) \\
\hline std error: & & & & 3 & $457.0033333^{\top}$ & $1071.12^{\top}$ & 594.3066667 \\
\hline 226.734633 & 342.815365 & $\begin{array}{r}187.438489 \\
22.4415584\end{array}$ & & 5 & 44.29 & 43.44 & 59.71666667 \\
\hline 8.09871801 & 6.29170883 & 7.12719674 & & 7 & $29.15^{F}$ & $17.04=$ & 35.86 \\
\hline 39.8640525 & 18.609288 & 8.2779815 & & 9 & $129.1366667^{\bar{T}}$ & $31.2^{F}$ & 24.53333333 \\
\hline
\end{tabular}




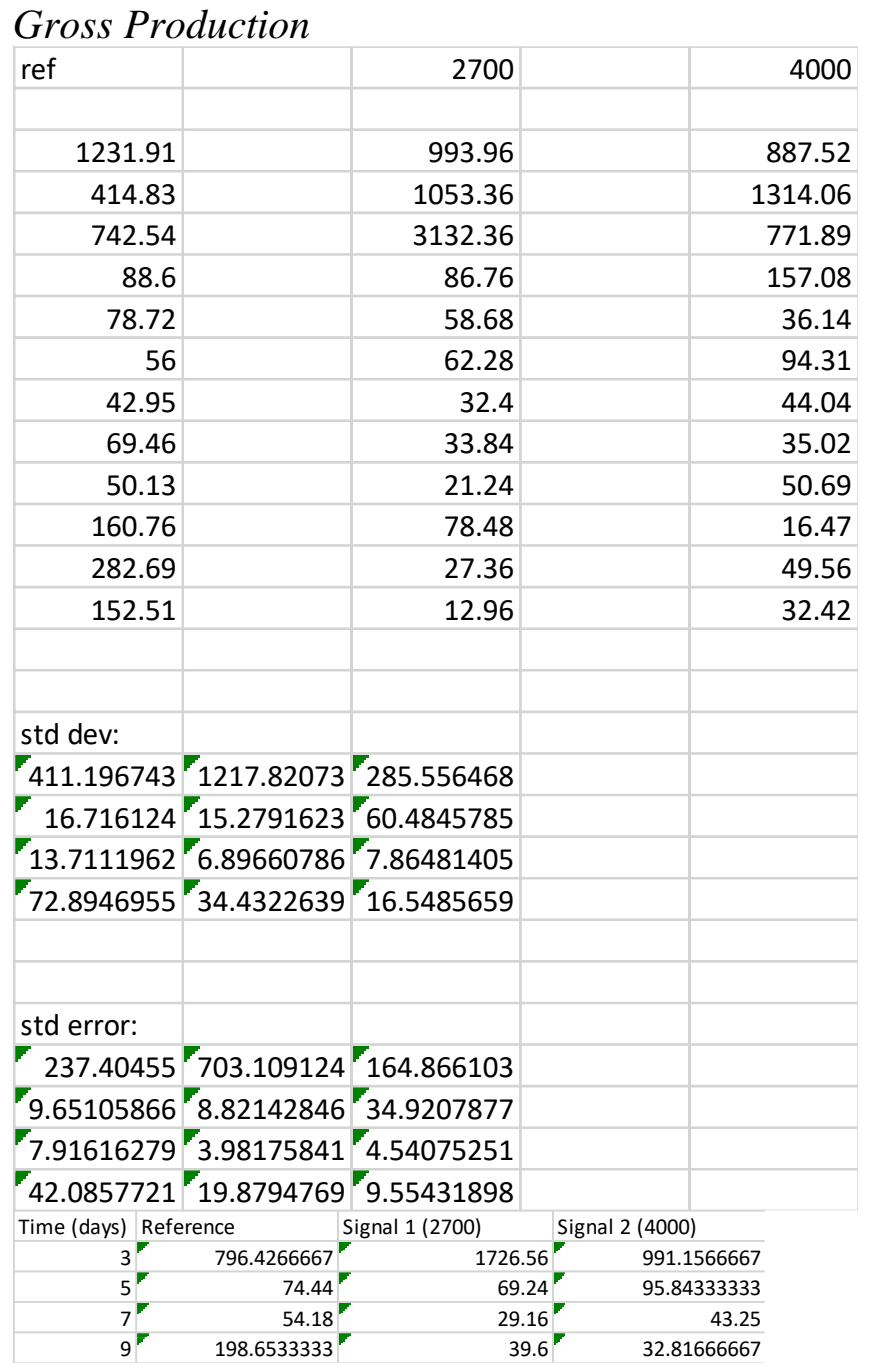


Microcystis aeurignosa raw growth data:

Raw and calculated counts from each day:

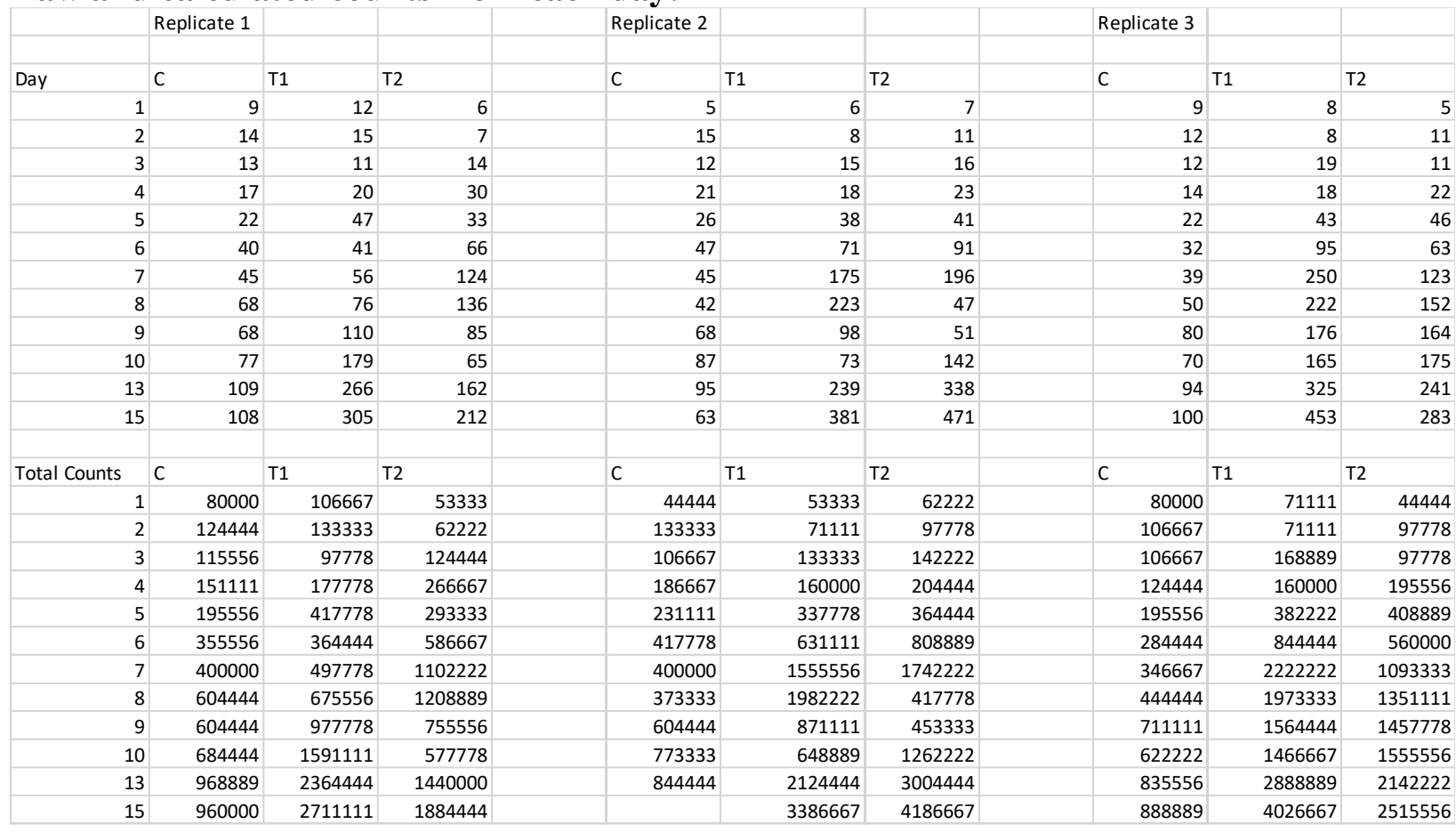

\section{Calculated growth rates and carrying capacities:}

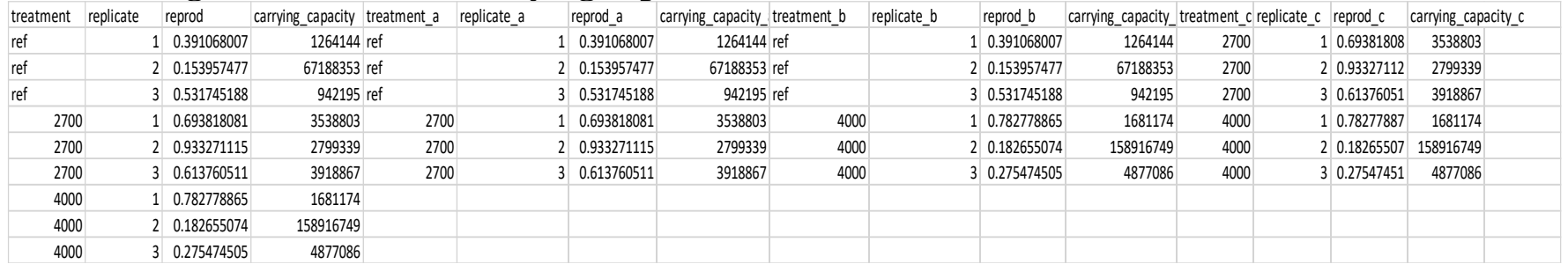


Microcystis aeruginosa raw photosynthetic data:

\section{Graph of Net Production:}

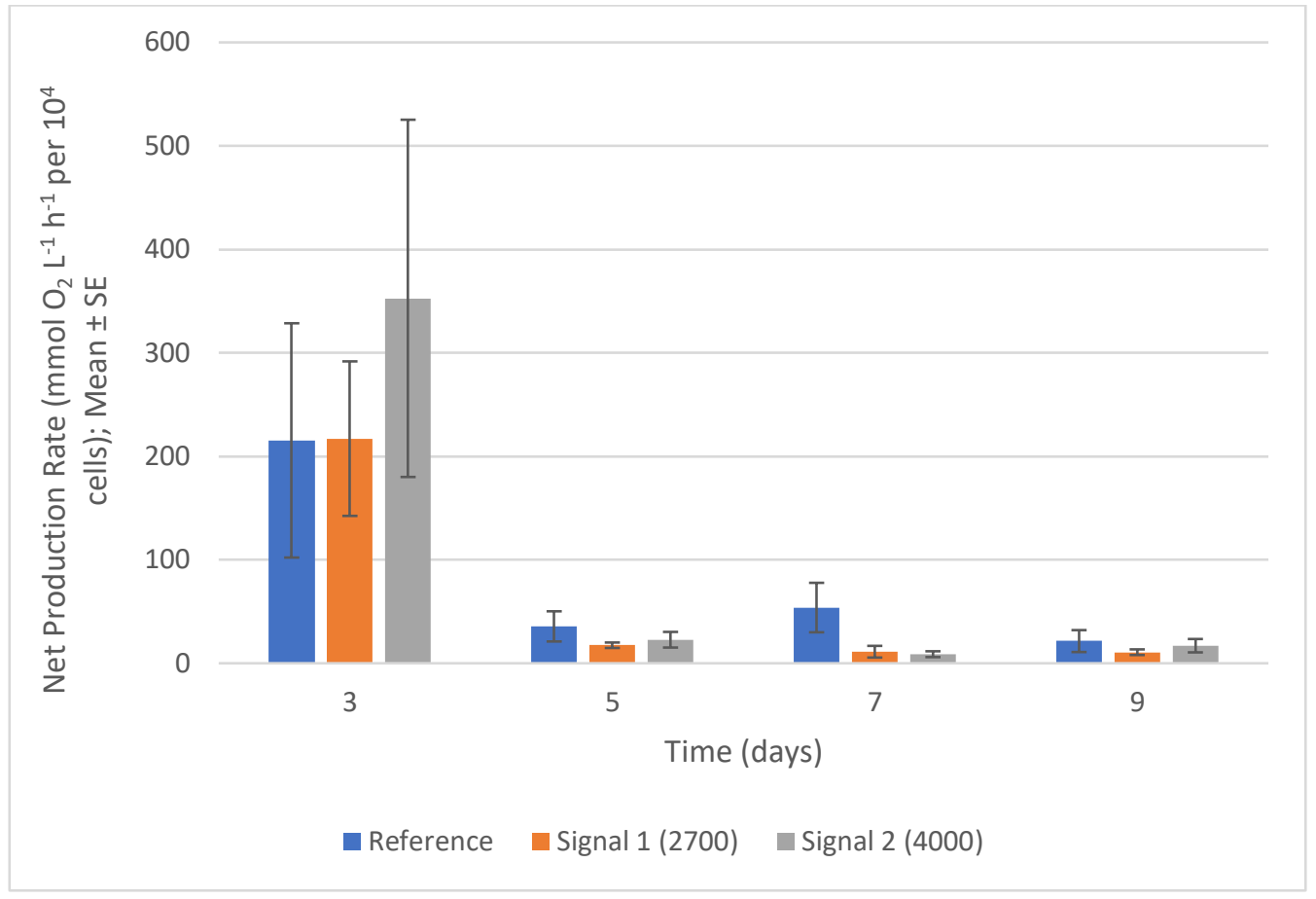

Fig. 3.8 M. aeruginosa mean \pm standard error net production rates over time across different electromagnetic field conditions 


\section{Graph of Gross Production:}

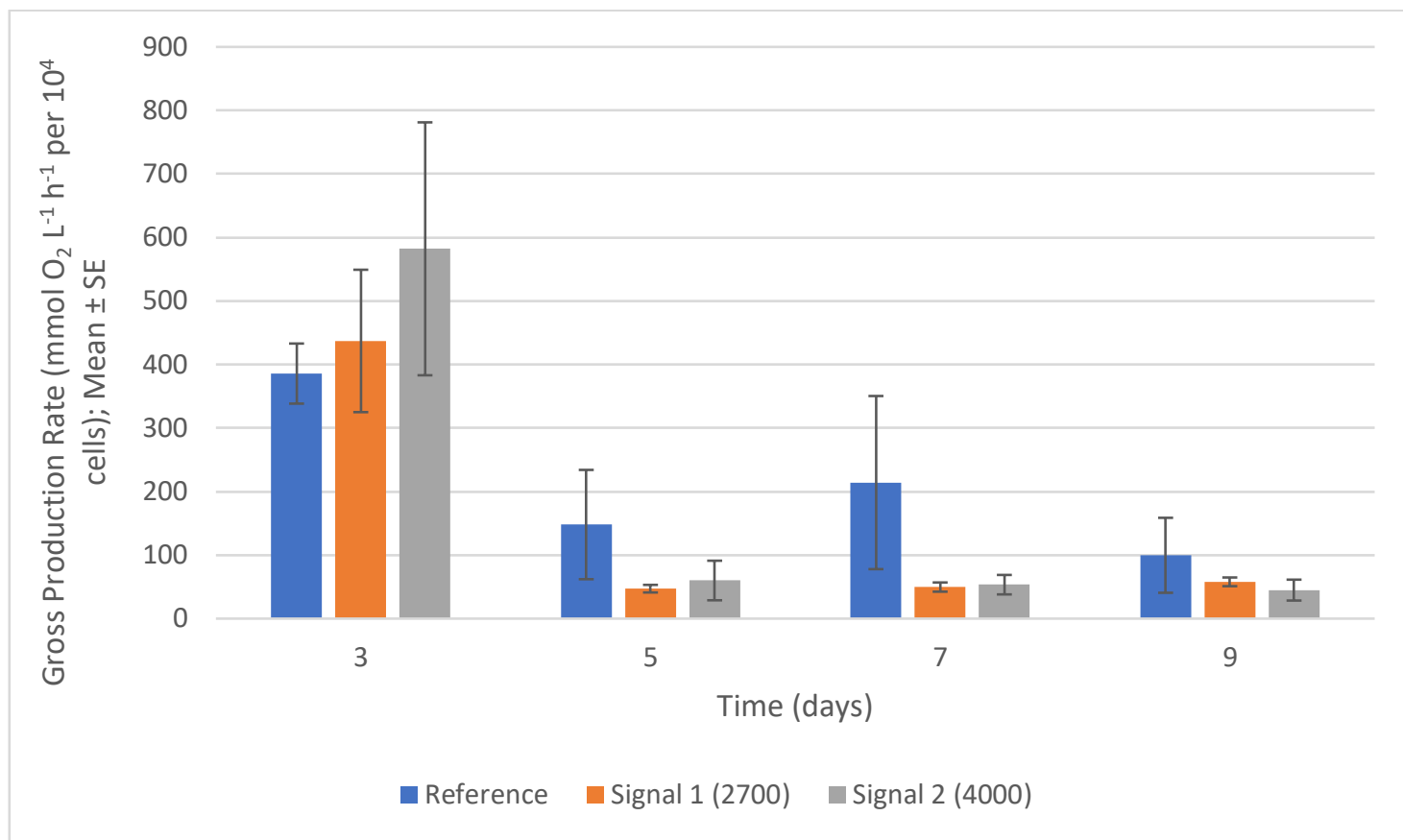

Fig. 3.9 M. aeruginosa mean \pm standard error gross production rates over time across different electromagnetic field conditions

\section{Calculated photosynthetic values from raw data:}

\begin{tabular}{|c|c|c|c|c|c|c|c|c|c|c|c|c|c|c|}
\hline Day & treatment & replicate & respiration & net_prod & gross_prod & resp_norm & net_norm & gross_norm & normalized time resp & net prod & gross prod & log resp & log net prod I & log gross prod \\
\hline & ref & 1 & 0.8258 & 0.1093 & 0.9351 & 0.00000715 & 0.00000095 & 0.00000809 & 257.27 & 34.05 & 291.32 & 2.41038496 & 1.53213028 & 2.464368035 \\
\hline & ref & 2 & 0.7343 & 0.5586 & 1.2929 & 0.00000688 & 0.00000524 & 0.00001212 & 247.83 & 188.53 & 436.35 & 2.39414589 & 2.27537346 & 2.639837369 \\
\hline & ref & 3 & 0.0184 & 1.2547 & 1.2731 & 0.00000017 & 0.00001176 & 0.00001194 & 6.21 & 423.46 & 429.67 & 0.79308908 & 2.62681321 & 2.63313584 \\
\hline & ref & 1 & 1.3874 & 0.3515 & 1.7389 & 0.00000709 & 0.00000180 & 0.00000889 & 255.41 & 64.71 & 320.11 & 2.40723286 & 1.8109569 & 2.505305862 \\
\hline & ref & 2 & 0.2285 & 0.1453 & 0.3738 & 0.00000099 & 0.00000063 & 0.00000162 & 35.59 & 22.63 & 58.23 & 1.55136791 & 1.35474734 & 1.76511994 \\
\hline & ref & 3 & 0.2526 & 0.1059 & 0.3585 & 0.00000129 & 0.00000054 & 0.00000183 & 46.50 & 19.50 & 66.00 & 1.66746416 & 1.28992743 & 1.819519456 \\
\hline & ref & 1 & 4.2816 & 1.1266 & 5.4082 & 0.00001070 & 0.00000282 & 0.00001352 & 385.34 & 101.39 & 486.74 & 2.5858486 & 2.00601226 & 2.687295253 \\
\hline & ref & 2 & 0.6063 & 0.2879 & 0.8942 & 0.00000152 & 0.00000072 & 0.00000224 & 54.57 & 25.91 & 80.48 & 1.73693008 & 1.41348417 & 1.905677175 \\
\hline & ref & 3 & 0.3966 & 0.3292 & 0.7258 & 0.00000114 & 0.00000095 & 0.00000209 & 41.19 & 34.19 & 75.37 & 1.61474371 & 1.53384961 & 1.877206582 \\
\hline & ref & 1 & 2.9587 & 0.937 & 3.6524 & 0.00000489 & 0.00000115 & 0.00000604 & 176.22 & 41.32 & 217.53 & 2.24604721 & 1.61611953 & 2.33752491 \\
\hline 4 & ref & 2 & 0.509 & 0.0867 & 0.5957 & 0.00000084 & 0.00000014 & 0.00000099 & 30.32 & 5.16 & 35.48 & 1.48166411 & 0.71296672 & 1.549974112 \\
\hline 4 & ref & 3 & 0.5602 & 0.3515 & 0.9117 & 0.00000079 & 0.00000049 & 0.00000128 & 28.36 & 17.79 & 46.15 & 1.452708 & 1.25029048 & 1.664217626 \\
\hline 1 & 2700 & 1 & 0.7165 & 0.9764 & 1.6929 & 0.00000733 & 0.00000999 & 0.00001731 & 263.88 & 359.64 & 623.16 & 2.42140648 & 2.55586799 & 2.794599569 \\
\hline 1 & 2700 & 2 & 0.9927 & 0.6832 & 1.6759 & 0.00000745 & 0.00000512 & 0.00001257 & 268.20 & 184.32 & 452.52 & 2.42845877 & 2.26557246 & 2.655637778 \\
\hline 1 & 2700 & 3 & 0.6025 & 0.5036 & 1.1061 & 0.00000357 & 0.00000298 & 0.00000655 & 128.52 & 107.28 & 235.80 & 2.10897072 & 2.03051876 & 2.372543801 \\
\hline 2 & 2700 & 1 & 0.4059 & 0.2434 & 0.6493 & 0.00000097 & 0.00000058 & 0.00000155 & 34.92 & 20.88 & 55.80 & 1.54307424 & 1.31973049 & 1.746634199 \\
\hline 2 & 2700 & 2 & 0.1553 & 0.1784 & 0.3337 & 0.00000046 & 0.00000053 & 0.00000099 & 16.56 & 19.08 & 35.64 & 1.21906033 & 1.28057837 & 1.551937695 \\
\hline 2 & 2700 & 3 & 0.4025 & 0.1301 & 0.5326 & 0.00000105 & 0.00000034 & 0.00000139 & 37.80 & 12.24 & 50.04 & 1.5774918 & 1.08778142 & 1.699317301 \\
\hline 3 & 2700 & 1 & 0.8799 & 0.0052 & 0.8851 & 0.00000177 & 0.00000001 & 0.00000178 & 63.72 & 0.36 & 64.08 & 1.80427577 & -0.4436975 & 1.806722503 \\
\hline 3 & 2700 & 2 & 1.2861 & 0.5888 & 1.8749 & 0.00000083 & 0.00000038 & 0.00000121 & 29.88 & 13.68 & 43.56 & 1.47538059 & 1.1360861 & 1.639087871 \\
\hline 3 & 2700 & 3 & 1.3599 & 1.1969 & 2.5568 & 0.00000061 & 0.00000054 & 0.00000115 & 21.96 & 19.44 & 41.40 & 1.34163234 & 1.28869626 & 1.617000341 \\
\hline 4 & 2700 & 1 & 1.7902 & 0.1495 & 1.9397 & 0.00000183 & 0.00000015 & 0.00000198 & 65.88 & 5.40 & 71.28 & 1.81875359 & 0.73239376 & 1.852967691 \\
\hline 4 & 2700 & 2 & 0.8302 & 0.3479 & 1.1781 & 0.00000095 & 0.00000040 & 0.00000135 & 34.20 & 14.40 & 48.60 & 1.53402611 & 1.15836249 & 1.686636269 \\
\hline 4 & 2700 & 3 & 1.8246 & 0.5253 & 2.3499 & 0.00000117 & 0.00000034 & 0.00000150 & 42.12 & 12.24 & 54.00 & 1.62448836 & 1.08778142 & 1.73239376 \\
\hline 1 & 4000 & 1 & 0.8851 & 0.5483 & 1.4334 & 0.00000711 & 0.00000441 & 0.00001152 & 256.05 & 158.62 & 414.66 & 2.40832112 & 2.20034699 & 2.617694657 \\
\hline 1 & 4000 & 2 & 1.1129 & 2.7536 & 3.8665 & 0.00000783 & 0.00001936 & 0.00002719 & 281.70 & 697.01 & 978.71 & 2.44979184 & 2.84323702 & 2.990654203 \\
\hline 1 & 4000 & 3 & 0.4097 & 0.5495 & 0.9592 & 0.00000419 & 0.00000562 & 0.00000981 & 150.84 & 202.32 & 353.16 & 2.17852689 & 2.30602877 & 2.547970623 \\
\hline 2 & 4000 & 1 & 0.8316 & 0.1544 & 0.986 & 0.00000284 & 0.00000053 & 0.00000336 & 102.06 & 18.95 & 121.01 & 2.00885556 & 1.27758868 & 2.08281882 \\
\hline 2 & 4000 & 2 & 0.0315 & 0.3774 & 0.4104 & 0.00000009 & 0.00000104 & 0.00000113 & 3.11 & 37.28 & 40.54 & 0.49298209 & 1.57147357 & 1.607879459 \\
\hline 2 & 4000 & 3 & 0.075 & 0.1359 & 0.2109 & 0.00000018 & 0.00000033 & 0.00000052 & 6.60 & 11.97 & 18.57 & 0.81975866 & 1.07791648 & 1.268773735 \\
\hline 3 & 4000 & 1 & 1.424 & 0.1344 & 1.5584 & 0.00000129 & 0.00000012 & 0.00000141 & 46.51 & 4.39 & 50.90 & 1.66754485 & 0.64243445 & 1.70671198 \\
\hline 3 & 4000 & 2 & 3.5519 & 0.3786 & 3.9305 & 0.00000204 & 0.00000022 & 0.00000226 & 73.39 & 7.82 & 81.22 & 1.86566008 & 0.89338021 & 1.909647371 \\
\hline 3 & 4000 & 3 & 0.4344 & 0.4262 & 0.8606 & 0.00000040 & 0.00000039 & 0.00000079 & 14.30 & 14.03 & 28.34 & 1.15543965 & 1.14716328 & 1.452351173 \\
\hline 4 & 4000 & 1 & 0.9406 & 0.4041 & 1.3447 & 0.00000124 & 0.00000053 & 0.00000178 & 44.82 & 19.25 & 64.07 & 1.65144046 & 1.28452476 & 1.806661502 \\
\hline 4 & 4000 & 2 & 0.3994 & 0.3383 & 0.7377 & 0.00000088 & 0.00000075 & 0.00000163 & 31.72 & 26.87 & 58.58 & 1.5012932 & 1.42918743 & 1.7677647 \\
\hline 4 & 4000 & 3 & 0.2993 & 0.1951 & 0.4944 & 0.00000021 & 0.00000013 & 0.00000034 & 7.39 & 4.82 & 12.21 & 0.86871683 & 0.68286896 & 1.086 \\
\hline
\end{tabular}




\section{Calculated averages and standard errors:}

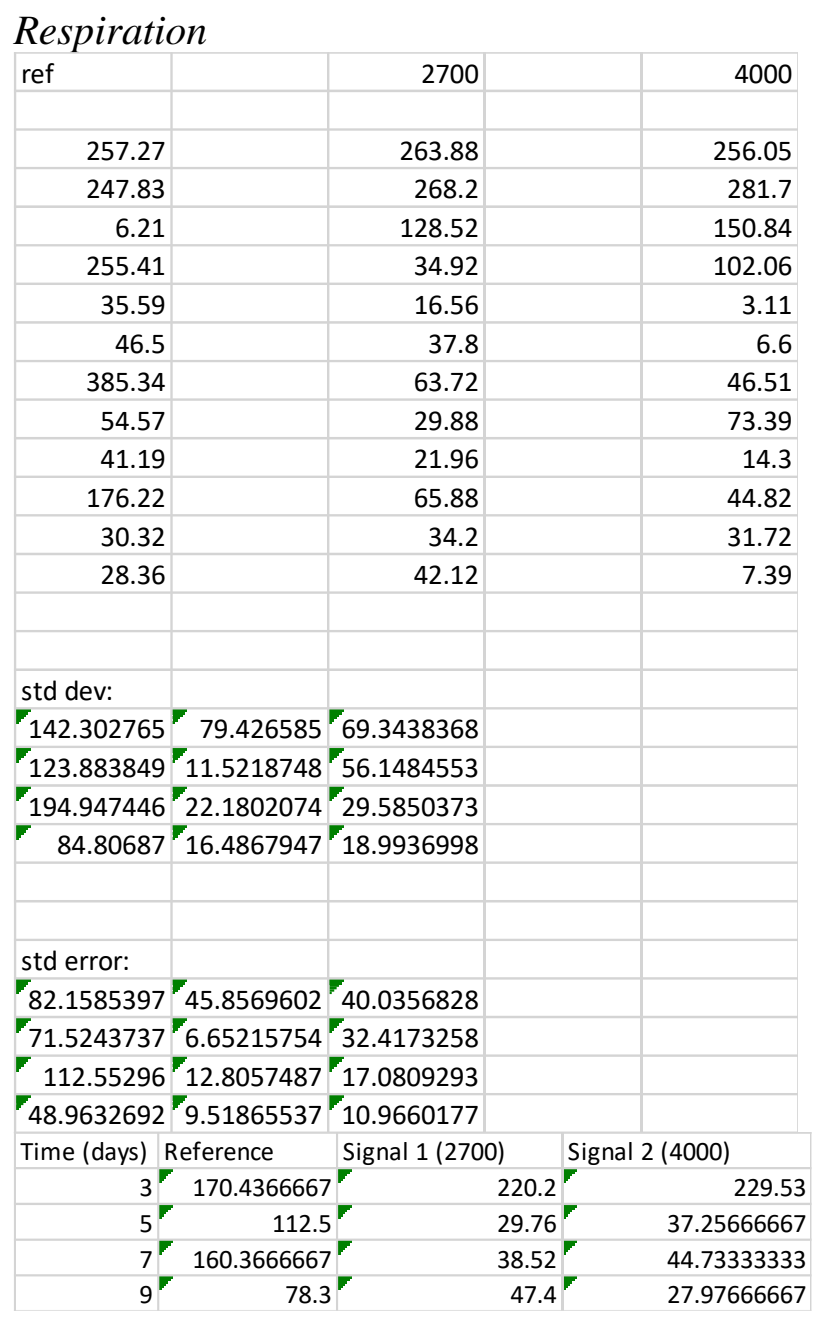




\section{Net Production}

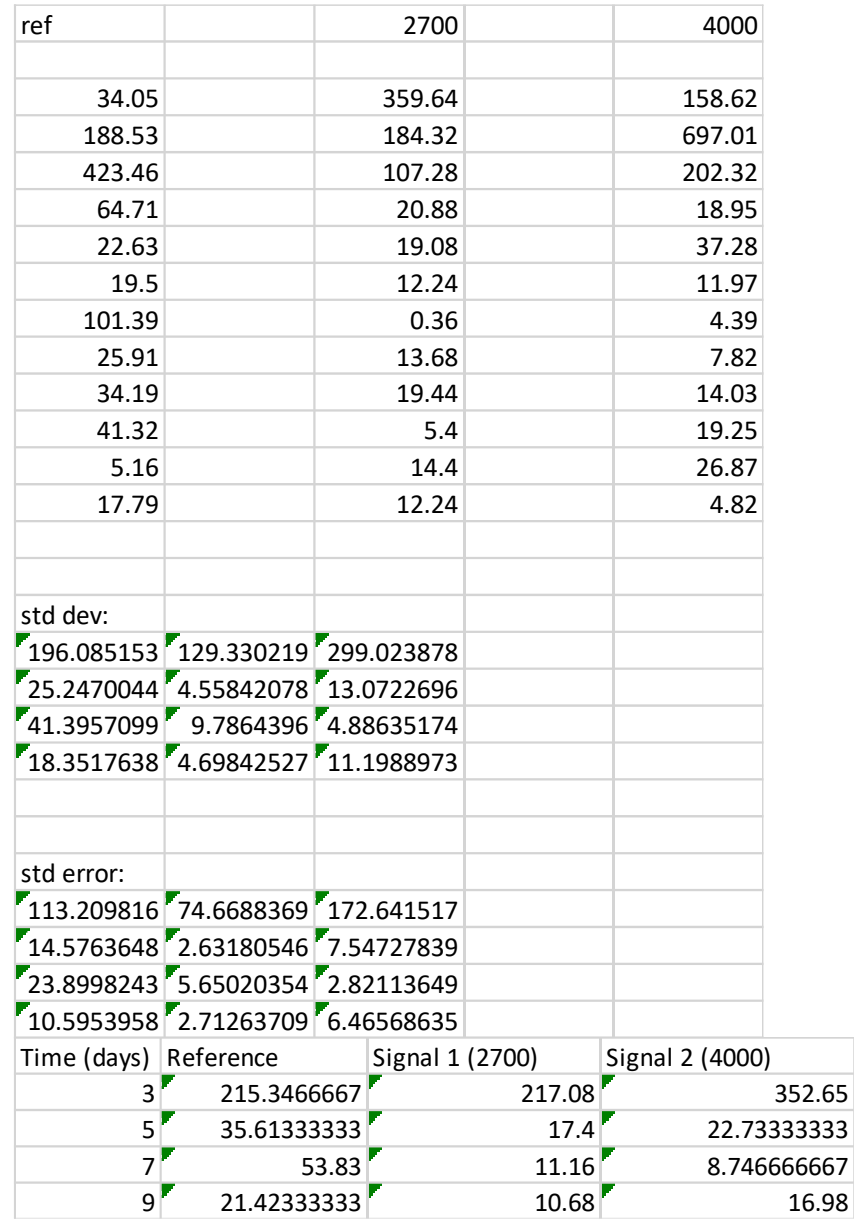




\section{Gross Production}

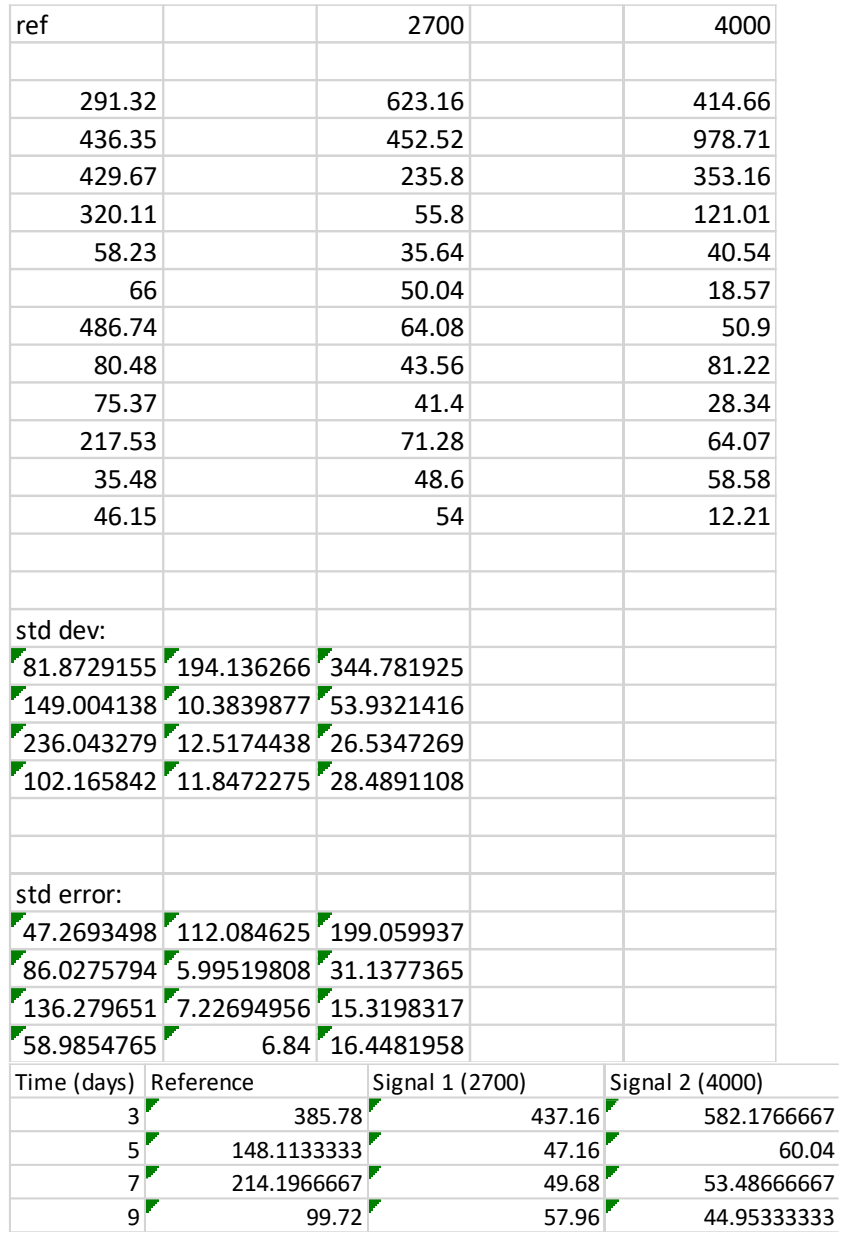




\section{References}

Alemán, E. I., Moreira, R. O., Lima, A. A., Silva, S. C., González-Olmedo, J. L., \& Chalfun, J. (2014). Effects of $60 \mathrm{~Hz}$ sinusoidal magnetic field on in vitro establishment, multiplication, and acclimatization phases of Coffea arabica seedlings. Bioelectromagnetics, 35(6), 414-425.

Anand, A., Nagarajan, S., Verma, A. P. S., Joshi, D. K., Pathak, P. C., \& Bhardwaj, J. (2012). Pre-treatment of seeds with static magnetic field ameliorates soil water stress in seedlings of maize (Zea mays L.).

Audus, L. J. (1960). Magnetotropism: a new plant-growth response. Nature, 185(4707), 132.

Bilalis, D. J., Katsenios, N., Efthimiadou, A., \& Karkanis, A. (2012). Pulsed electromagnetic field: an organic compatible method to promote plant growth and yield in two corn types. Electromagnetic biology and medicine, 31(4), 333-343.

Chukhutsina, V. U., Büchel, C., \& van Amerongen, H. (2013). Variations in the first steps of photosynthesis for the diatom Cyclotella meneghiniana grown under different light conditions. Biochimica et Biophysica Acta (BBA)-Bioenergetics, 1827(1), 10-18.

Deamici, K. M., Costa, J. A. V., \& Santos, L. O. (2016). Magnetic fields as triggers of microalga growth: evaluation of its effect on Spirulina sp. Bioresource technology, 220, 62-67.

Deamici, K. M., Santos, L. O., \& Costa, J. A. V. (2018). Use of static magnetic fields to increase

$\mathrm{CO} 2$ biofixation by the microalga Chlorella fusca. Bioresource technology, 276, 103109.

Dhawi, F., \& Al-Khayri, J. M. (2009). Magnetic fields induce changes in photosynthetic pigments content in date palm (Phoenix dactylifera L.) seedlings. The Open Agriculture Journal, 3(1).

Efthimiadou, A., Katsenios, N., Karkanis, A., Papastylianou, P., Triantafyllidis, V., Travlos, I., $\&$

Bilalis, D. J. (2014). Effects of presowing pulsed electromagnetic treatment of tomato seed on growth, yield, and lycopene content. The Scientific World Journal, 2014.

Eşitken, A., \& Turan, M. (2004). Alternating magnetic field effects on yield and plant nutrient element composition of strawberry (Fragaria x ananassa cv. Camarosa). Acta Agriculturae Scandinavica, Section B-Soil \& Plant Science, 54(3), 135-139.

Evans J. R. (2013). Improving photosynthesis. Plant physiology, 162(4), 1780-1793. https://doi.org/10.1104/pp.113.219006 
Guillard, R. R., \& Lorenzen, C. J. (1972). YELLOW-GREEN ALGAE WITH CHLOROPHYLLIDE C 1, 2. Journal of Phycology, 8(1), 10-14.

Hadjoudja, S., Deluchat, V., \& Baudu, M. (2010). Cell surface characterisation of Microcystis aeruginosa and Chlorella vulgaris. Journal of colloid and interface science, 342(2), 293-299.

Hirano, M., Ohta, A., \& Abe, K. (1998). Magnetic field effects on photosynthesis and growth of the cyanobacterium Spirulina platensis. Journal of fermentation and bioengineering, 86(3), 313-316.

Hunt, R., Zavalin, A., Bhatnagar, A., Chinnasamy, S., \& Das, K. (2009). Electromagneticbiostimulation of living cultures for biotechnology, biofuel and bioenergy applications. International journal of molecular sciences, 10(10), 4515-4558.

IARC Working Group on the Evaluation of Carcinogenic Risks to Humans, \& International Agency for Research on Cancer. (2002). Non-ionizing radiation. In Non-ionizing radiation (pp. 1-429).

Jan, L., Fefer, D., Košmelj, K., Gaberščik, A., \& Jerman, I. (2015). Geomagnetic and strong static magnetic field effects on growth and chlorophyll a fluorescence in Lemna minor. Bioelectromagnetics, 36(3), 190-203.

Javed, N., Ashraf, M., Akram, N. A., \& Al-Qurainy, F. (2011). Alleviation of adverse effects of drought stress on growth and some potential physiological attributes in maize (Zea mays L.) by seed electromagnetic treatment. Photochemistry and Photobiology, 87(6), 1354-1362.

Katsenios, N., Kavvadias, V., Theocharopoulos, S., Bilalis, D., Ioannou, Z., Papadopoulos, A., $\&$ Liakopoulou, N. (2015). Influence of Pulsed Electromagnetic Field on Plant Growth, Nutrient Absorption and Yield of Durum Wheat. Notulae Scientia Biologicae, 7(4), 505-509.

Kirschbaum, M. U. (2011). Does enhanced photosynthesis enhance growth? Lessons learned from CO2 enrichment studies. Plant physiology, 155(1), 117-124.

Krienitz, L., Huss, V. A., \& Bock, C. (2015). Chlorella: 125 years of the green 
survivalist. Trends in plant science, 20(2), 67-69.

Kühn, S. F., \& Köhler-Rink, S. (2008). pH effect on the susceptibility to parasitoid infection in the marine diatom Coscinodiscus spp.(Bacillariophyceae). Marine biology, 154(1), 109-116.

Li, Z. Y., Guo, S. Y., Li, L., \& Cai, M. Y. (2007). Effects of electromagnetic field on the batch cultivation and nutritional composition of Spirulina platensis in an air-lift photobioreactor. Bioresource Technology, 98(3), 700-705.

Maffei, M. E. (2014). Magnetic field effects on plant growth, development, and evolution. Frontiers in plant science, 5, 445.

Mitrovic, S. M., Chessman, B. C., Davie, A., Avery, E. L., \& Ryan, N. (2008). Development of blooms of Cyclotella meneghiniana and Nitzschia spp.(Bacillariophyceae) in a shallow river and estimation of effective suppression flows. Hydrobiologia, 596(1), 173-185.

Novitsky, Y. I., Novitskaya, G. V., Kocheshkova, T. K., Nechiporenko, G. A., \& Dobrovol'Skii,

M. V. (2001). Growth of green onions in a weak permanent magnetic field. Russian Journal of Plant Physiology, 48(6), 709-716.

O’neil, J. M., Davis, T. W., Burford, M. A., \& Gobler, C. J. (2012). The rise of harmful cyanobacteria blooms: the potential roles of eutrophication and climate change. Harmful algae, 14, 313-334.

Poirier, D. G., Westlake, G. F., \& Abernethy, S. G. (1988). Daphnia magna acute lethality toxicity test protocol.

Radhakrishnan, R., \& Kumari, B. D. R. (2012). Pulsed magnetic field: a contemporary approach

offers to enhance plant growth and yield of soybean. Plant Physiology and Biochemistry, 51, 139-144.

Reina, F. G., Pascual, L. A., \& Fundora, I. A. (2001). Influence of a stationary magnetic field on water relations in lettuce seeds. Part II: experimental results. Bioelectromagnetics: Journal of the Bioelectromagnetics Society, The Society for Physical Regulation in Biology and Medicine, The European Bioelectromagnetics Association, 22(8), 596-602.

Rochalska, M. (2005). Influence of frequent magnetic field on chlorophyll content in leaves of sugar beet plants. Nukleonika, 50, 25-28.

Shine, M. B., \& Guruprasad, K. N. (2012). Impact of pre-sowing magnetic field exposure of 
seeds to stationary magnetic field on growth, reactive oxygen species and photosynthesis of maize under field conditions. Acta physiologiae plantarum, 34(1), 255-265.

Shine, M. B., Guruprasad, K. N., \& Anand, A. (2011). Enhancement of germination, growth, and

photosynthesis in soybean by pre-treatment of seeds with magnetic field. Bioelectromagnetics, 32(6), 474-484.

Small, D. P., Hüner, N. P., \& Wan, W. (2012). Effect of static magnetic fields on the growth, photosynthesis and ultrastructure of Chlorella kessleri microalgae. Bioelectromagnetics, 33(4), 298-308.

Stanier, R. Y., \& Cohen-Bazire, G. (1977). Phototrophic prokaryotes: the cyanobacteria. Annual review of microbiology, 31(1), 225-274.

Tu, R., Jin, W., Xi, T., Yang, Q., Han, S. F., \& Abomohra, A. E. F. (2015). Effect of static magnetic field on the oxygen production of Scenedesmus obliquus cultivated in municipal wastewater. Water research, 86, 132-138.

Turker, M., Temirci, C., Battal, P., \& Erez, M. E. (2007). The effects of an artificial and static magnetic field on plant growth, chlorophyll and phytohormone levels in maize and sunflower plants. Phyton Ann. Rei Bot, 46, 271-284.

Vashisth, A., \& Joshi, D. K. (2017). Growth characteristics of maize seeds exposed to magnetic field. Bioelectromagnetics, 38(2), 151-157.

Waldbauer, J. R., Sherman, L. S., Sumner, D. Y., \& Summons, R. E. (2009). Late Archean molecular fossils from the Transvaal Supergroup record the antiquity of microbial diversity and aerobiosis. Precambrian Research, 169(1-4), 28-47.

Weiss, R. F., 1970. The solubility of nitrogen, oxygen, and argon in water and seawater. Deep Sea Res. 17: 721-735.

Wilhelm, C., Büchel, C., Fisahn, J., Goss, R., Jakob, T., LaRoche, J., ... \& Valentin, K. (2006). The regulation of carbon and nutrient assimilation in diatoms is significantly different from green algae.

Yaycili, O., \& Alikamanoglu, S. (2005). The effect of magnetic field on Paulownia tissue cultures. Plant Cell, Tissue and Organ Culture, 83(1), 109-114. 
